\title{
El Panorama del Español en Estados Unidos
}

\author{
Anna Orlovska* \\ Universitat Rovira i Virgili, Tarragona, Spain
}

\begin{abstract}
The goal of this paper is to reflect on the situation of the Spanish language in the USA, considering basic concepts in Sociolinguistics such as identity, attitude and prestige. Forecasts indicate that by 2050 USA will be the country with the largest number of Spanish speakers. These forecasts are based almost exclusively on the number of people that will costitute the Latin-community in the coming years. In this paper, we consider that statements like the above may be moot if we analyze the concrete situation in which Spanish speakers are in the USA and the attitudes and opinions arising from the use of this language in the United States. In order to get answers to basic questions -namely, in the USA, regarding the relationship Spanish-English, we find a situation of bilingualism or diglossia?; What is the future of Spanish in the USA? What role will play the Spanish language in the USA in the coming years?-, in this paper we analyze: 1) the presence of the Spanish language in the USA; 2) the language planning of the central government of the USA; 3) the use of the language by the Spanish speakers in USA; and 4) the attitude of English speakers towards Spanish language.
\end{abstract}

Keywords: Bilingualism, Spanish, USA.

Resumen. El objetivo de este artículo es reflexionar sobre la situación de la lengua española en EE.UU., teniendo en cuenta conceptos básicos en sociolingüística como

\footnotetext{
* Author's address:

Departament de Filologies Romàniques

Universitat Rovira i Virgili

Av. Catalunya 35, 43002 Tarragona, Spain

E-mail anna.orlovska@estudiants.urv.cat
} 
identidad, actitud y prestigio. Las previsiones señalan que, en 2050, EE.UU. será el país con el mayor número de hispanohablantes. Estas previsiones se basan casi exclusivamente en el número de personas que compondrá la comunidad latina en los próximos años. En este trabajo, consideramos que afirmaciones como las anteriores pueden ser discutibles si analizamos la situación concreta en la que se encuentran los hablantes de español en EE.UU. y las actitudes y opiniones que suscita el uso de esta lengua en territorio estadounidense. Con el objetivo de obtener respuesta a una serie de preguntas -a saber, en EE.UU., en lo que respecta a la relación español-inglés, nos encontramos con una situación de ¿bilingüismo o diglosia?; ¿Qué futuro tiene el español en EE.UU.? ¿Qué papel jugará la lengua española en Estados Unidos en los próximos años?-, en este trabajo analizamos: 1) la presencia de la lengua española en Estados Unidos; 2) la planificación lingüística del gobierno central de Estados Unidos; 3) el uso de la lengua por parte de los hispanohablantes de EE.UU.; y 4) la actitud de los anglosajones hacia el español.

Palabras clave: Bilingüismo, español, Estados Unidos.

\section{Introducción}

El español en los Estados Unidos -su presencia, su situación y su posible futuro- es el objetivo de numerosos estudios. Esto se debe a que Estados Unidos es un país multicultural, con mezcla de razas y, por consiguiente, con una gran variedad de lenguas en su territorio, de entre las que destaca el español. De hecho, el español es la segunda lengua más hablada en la Unión Norteamericana, después del inglés. Esta situación se explica no solo por la historia del continente -los países en el Suroeste de la Unión-, sino también como consecuencia del fenómeno de la inmigración y de la globalización.

Dejando a un lado la larga historia del español en territorio estadounidense, la expansión de la lengua española en el continente en las últimas décadas, la creciente demografía de la población hispana y la propaganda de la lengua y la cultura realizada por las instituciones españolas han llevado a muchos expertos a afirmar que Estados Unidos será en 2050 el primer país hispanohablante del mundo, razón por la cual es muy habitual encontrar afirmaciones como las siguientes:

Los Estados Unidos son hoy el segundo país hispanohablante del mundo, por el número de sus hablantes. Este hecho había sido proyectado para 2030 (Británica Word Data), pero ya es una realidad. Las proyecciones para el año 2050 convertirían a los Estados Unidos en el 
primero, desplazando a México de este sitial y, por supuesto, a los que hasta hace muy poco tiempo estaban tras él: España, Colombia y la Argentina (López Morales 2008:1036).

$\mathrm{O}$ artículos en periódicos con titulares como "El idioma español, en la cima del universo" (www.abc.es); "El español ganará la partida al inglés" (elpaís.com); "Estados Unidos podría ser el país con más hispanohablantes en 2050" (www.elmundo.es).

Es lógico llegar a estas conclusiones partiendo de los informes de diferentes organismos que se ocupan del español y que ofrecen estadísticas variadas. No obstante, a veces, los números no son suficientes para determinar en qué situación se encuentra una lengua en un territorio determinado y qué futuro le espera. Creemos que la realidad de diversos grupos lingüísticos que coexisten no puede analizarse únicamente a partir de unas estadísticas que representan a una comunidad de habla en bloque. Pensamos que es necesario analizar la opinión de individuos concretos, ya que son estos hablantes particulares los que hacen uso de la lengua y, por lo tanto, son ellos los que determinan el futuro de la lengua y su posible modificación. Consideramos que afirmaciones como las anteriores pueden ser discutibles si analizamos por un lado la situación concreta en la que se encuentran los hablantes de español en EE.UU. y, por otro, las actitudes y opiniones que suscita el uso de esta lengua en territorio estadounidense.

El objetivo del trabajo que presentamos aquí es reflexionar sobre la situación de la lengua española en la Unión Norteamericana, teniendo en cuenta conceptos básicos en sociolingüística como identidad, actitud y prestigio, ya que creemos que estos fenómenos afectan directamente al uso, mantenimiento y difusión del español en EE.UU. En concreto, analizamos: 1) La presencia de la lengua española en Estados Unidos; 2) la planificación lingüística del gobierno central de Estados Unidos; 3) el uso de la lengua por parte de los hispanohablantes en la Unión; y 4) la actitud de los anglosajones hacia el español.

A partir del análisis de estos ámbitos que afectan al español directamente, pretendemos llegar a una serie de conclusiones que nos permitan aclarar cuál es la realidad lingüística de EE.UU. En concreto, queremos encontrar respuesta a las dos preguntas siguientes:

1. En EE.UU., en lo que respecta a la relación español-inglés, nos encontramos con una situación de ¿bilingüismo o diglosia? 
2. ¿Qué futuro tiene el español en EE.UU.? ¿Qué papel jugará la lengua española en Estados Unidos en los próximos años?

Para realizar nuestro estudios hemos extraído de la bibliografía general sobre el español en EE.UU. las ideas más recurrentes sobre la situación actual y el futuro de esta lengua en territorio norteamericano; hemos revisado los datos y estadísticas oficiales que ofrecen las instituciones públicas americanas, las universidades y otras organizaciones que se ocupan del español en EE.UU.; hemos analizado una serie de vídeos (más de 200) en los que hablantes hispanos de EE.UU. ofrecen sus opiniones sobre el uso del español en territorio estadounidense; hemos elaborado una encuesta propia para conocer la actitud de los estadounidenses respecto a la lengua española; y, finalmente, hemos contrastado los datos oficiales con las opiniones de los hablantes y la encuesta realizada para poder extraer conclusiones sobre la situación real del español en EE.UU.

Este trabajo se organiza de la siguiente manera. En primer lugar, se establecen los conceptos sociolingüísticos en los que se va a basar nuestro análisis del español en EE.UU. En segundo lugar, tras un breve repaso al origen de la presencia del español en EE.UU., realizamos un análisis que pretende observar la presencia del español en el ámbito formal a nivel nacional. En concreto, nos ocupamos de la administración pública y jurídica, de los medios de comunicación $\mathrm{y}$, por supuesto, del ámbito más relevante en las lenguas minoritarias, la educación. Nos centramos especialmente en este último ámbito, porque creemos que es uno de los que más influye a la hora de elegir la lengua. Por último, analizamos el uso que los hispanos hacen del español en la comunidad estadounidense desde una perspectiva claramente sociolingüística, centrándonos en conceptos como prestigio, actitud, identidad. Para poder ejemplificar el uso y las actitudes, analizamos de forma particular la situación del español en Texas.

\section{Contacto de Lenguas}

El contacto de lenguas es un fenómeno que implica la convivencia de diferentes grupos lingüísticos que comparten el espacio físico y las normas sociales de un determinado territorio. Trudgill y Hernández Campoy (2007: 75) definen el contacto lingüístico como una situación en la que "grupos de dos o más 
hablantes que no tienen una lengua materna común están o entran en contacto social". Por tanto, en situación de contacto lingüístico, diferentes grupos lingüísticos comparten territorio $\mathrm{y}$, a pesar de tener idiomas maternos diferentes, suelen compartir una lengua en común fijada por las normas políticas y sociales del territorio en el que conviven.

Las situaciones de contacto lingüístico suelen ser el resultado de diferentes circunstancias históricas que desembocan en esta realidad. Siguán y Mackey (1989: 40-43) enumeran una serie de factores históricos que suelen provocar situaciones de contacto de lenguas:

- Expansión. Se trata de pueblos que a lo largo de la historia se han ido expandiendo y ampliando sus fronteras y con este proceso llevan consigo tanto su cultura como su lengua. Un ejemplo claro es el latín que penetró en la Península con la expansión del Imperio Romano y fue la base de todas las lenguas románicas actuales.

- Unificación. Hace referencia a la unificación política; es decir, un grupo étnico impone tanto su lengua como su cultura, y esto queda reflejado en la necesidad de una lengua común para la comunicación entre los diferentes puntos del territorio. El ámbito de la educación es en el que más se manifiesta la imposición lingüística; el resultado de la unificación. Un ejemplo podría ser el actual estado de Texas que en los años anteriores a 1800 formaba parte del territorio de México. Una vez que este territorio fue absorbido por los pueblos anglosajones, como resultado de la guerra de México, el inglés se convirtió en la lengua oficial y fue impuesta a los hispanohablantes que no abandonaron el nuevo territorio anglosajón.

- Situaciones postcoloniales. Esta situación queda muy bien reflejada tomando como ejemplo los procesos de independencia en América del Sur (18001830). Tratándose de la lengua, en primer lugar, hay que mencionar que, los regímenes coloniales se daban en territorios que no tenían estructuras políticas y que contaban con una gran variedad de lenguas indígenas; en segundo lugar, a la hora de definir las fronteras de los diferentes territorios no tenían en cuenta la gran diversidad étnica y cultural de los pueblos afectados, razón por la cual, después de los procesos de independencia, los Estados de América del Sur tienen una realidad lingüística plurilingüe muy compleja.

- Inmigración. Estamos ante el masivo traslado de personas hacia los países industrializados que, a su vez, llevan consigo su lengua. Este fenómeno se 
ha producido a lo largo de la historia, y, en la actualidad, sigue produciéndose. Por ejemplo, la inmigración de origen mexicana en el Suroeste de los Estados Unidos. Los inmigrantes llevan consigo su lengua y sus costumbres al nuevo territorio. La integración de los recién llegados se manifiesta en la adopción de la lengua inglesa que lleva hacia el bilingüismo y, en algunas ocasiones, hacia el monolingüismo anglófono a lo largo de las generaciones.

- Cosmopolitismo. Hace referencia a la globalización que se caracteriza principalmente por la necesidad del uso de las lenguas francas para la comunicación internacional. Esto puede observarse primordialmente en las grandes ciudades cosmopolitas, las sedes de organismos internacionales, etc., pero también con las nuevas tecnologías que implican una nueva forma de comunicación a distancia.

En un territorio que ha experimentado cualquiera de los fenómenos mencionados anteriormente conviven personas que pertenecen a diferentes grupos étnicos con sus respectivas lenguas y culturas. El contacto de esas lenguas es inevitable en la comunicación cotidiana y desemboca en el fenómeno conocido como bilingüismo, en algunos casos diglosia. El bilingüismo es un fenómeno que ha llamado mucho la atención de los estudiosos desde finales del siglo XIX. A pesar de ser un término muy utilizado, y familiar para cualquier hablante, su definición técnica presenta importantes problemas. En el apartado siguiente intentaremos proporcionar una definición.

\section{Bilingüismo y Diglosia}

A la hora de describir las situaciones de bilingüismo, la mayor parte de los lingüistas recurren a las definiciones proporcionadas por Bloomfield (1933) y Macnamara (1969). Estas definiciones representan dos polos opuestos, están basadas en el concepto de competencia y hacen referencia al bilingüismo como fenómeno individual. Bloomfield (1933) consideraba que para considerarse bilingüe, un hablante debía poseer "un dominio de dos o más lenguas igual que el de un nativo". Para Macnamara (1969), en cambio, una persona puede ser clasificada como bilingüe "si además de las habilidades en su primera lengua, tiene algunas habilidades en una de las cuatro modalidades (hablar, entender, escribir, leer) de la segunda lengua" (citado por Appel \& Muysken 1996: 11). Como puede observarse, estas definiciones tratan el conocimiento que un hablante tiene de las lenguas y, por lo tanto, es muy difícil discriminar adecuadamente y aplicarlas a individuos concretos. Por un lado, si seguimos la 
definición de Bloomfield (1933), es improbable encontrar un hablante bilingüe con capacidad de dominar las dos lenguas con el nivel de competencia de un monolingüe nativo de cada lengua. Por otro parte, si aplicamos la definición de Macnamara (1969), la gran mayoría de la población sería bilingüe, ya que es frecuente encontrar personas que, además de dominar el idioma materno, son capaces de leer en una segunda lengua, aunque no tengan el nivel suficiente para hablar en esa lengua. Este tipo de definiciones basadas en la competencia suele llevar a discusiones porque, como pone de manifiesto Skutnabb-Kangas (1981: 85), aunque se intentara aplicar las definiciones basadas en la competencia lingüística, ningún autor especifica ni el nivel de competencia que un bilingüe supuestamente debería poseer ni con qué competencia se ha de comparar la competencia del bilingüe, es decir, con la de un monolingüe o la de otro bilingüe. Por otro lado, el nivel de dominio lingüístico necesario suele aplicarse a la segunda lengua, dando por sentado el dominio completo de la primera. Por último, se sugiere implícitamente como ideal el bilingüismo equilibrado. Del mismo modo, Titone (1976), partiendo de las observaciones de W. F. Mackey (2012), considera que:

Esta variedad de definiciones es precisamente lo que ha venido obstaculizando el análisis y explicación de los fenómenos del bilingüismo. Es más, entre tales definiciones, el elemento de máxima confusión ha sido la insistencia en el criterio de no distinción del uso nativo. En realidad, es de hecho imposible definir el grado de perfección en el cual un buen hablante extranjero pasa a convertirse en bilingüe. En segundo lugar, no todos los hablantes nativos son igualmente sensibles, no todos poseen la misma riqueza de vocabulario ni igual versatilidad en la selección de las estructuras (Titone 1976: 14).

Como puede observarse, estamos ante el conflicto entre la competencia lingüistica y la competencia comunicativa, porque, como afirman Christian Abelló Contesse y Christoph Ehlers (2010: 7): "la competencia lingüística no presupone necesariamente un manejo comunicativo de las lenguas del hablante". O como lo expresa Siguán (2001):

Los comportamientos del sujeto no están solo determinados por su competencia en las dos lenguas de habla. Dependen igualmente de las situaciones en las que las utiliza y por tanto de las funciones que cumplen en su existencia (Siguán 2001: 28). 
Otros estudiosos, conscientes de que el conocimiento no tiene nada que ver con el uso de lenguas, optan por las definiciones cuyo principio base es el uso de lenguas que un hablante bilingüe hace de ellas. Para Weinreich (1974: 17) "Las costumbres de usar alternativamente dos lenguas será llamada bilingüismo y las personas que tienen esa costumbre serán llamadas bilingües". Montrul (2013: 8) considera bilingüe a "una persona que tiene conocimiento estable y control funcional de dos o más lenguas, sin importar el nivel de conocimiento o si las lenguas se usan en la vida cotidiana." Siguán (2001) propone la siguiente definición:

Llamamos bilingüe el sujeto que posee dos sistemas lingüísticos -dos lenguas- con amplitud y profundidad similar y que es capaz de utilizarlos en cualquier situación de su contexto social con parecida facilidad y eficacia (Siguán 2001: 29).

Estas definiciones demuestran que la competencia comunicativa tiene un gran peso a la hora de acercase al perfil de un individuo bilingüe, porque una persona bilingüe puede no poseer la misma eficacia y competencia en habilidades lingüísticas de comprensión (audición, lectura) y de expresión (oral, escritura). Podemos concluir, siguiendo a Titone (1976: 14), que el bilingüismo es un fenómeno de grado. Este lingüista se basa en la propuesta de Mackey (2012) y trata el bilingüismo como un concepto relativo, limitando su definición al género de actividad lingüistica ejercida, ya que no se plantea la pregunta “¿Es bilingüe este determinado individuo?, sino ¿En qué aspecto es bilingüe?”. En esta línea se sitúa también la definición propuesta por Christian Abelló Contesse y Christoph Ehlers (2010):

Un concepto genérico con el que se designa el uso habitual o frecuente de dos o más lenguas por parte de un hablante o de una comunidad lingüística, normalmente dentro de ciertos contextos sociales y para ciertos fines comunicativos. [...] El bilingüismo es asimismo, un fenómeno relativo y no absoluto en el sentido de que no presupone un nivel único ni excluyente de capacidad comunicativa (proficiency), sino diferentes grados. El hablante bilingüe es, pues, quien hace uso frecuente de más de una lengua, una de las cuales es dominante y la(s) otra(s) no dominante(s), encontrándose la(s) última(s) en unos niveles suficientemente avanzados de desarrollo que permitan los grados comparativamente altos de estabilidad formal y de automaticidad comu- 
nicativa que caracterizan el uso habitual de cualquier lengua (Abelló Contesse \& Ehlers 2010: 8-9).

Todas estas definiciones señalan la importancia que tiene el uso de las lenguas, ya que el uso determina el grado de competencia lingüística; es decir, a mayor uso, mayor competencia. Por otra parte, teniendo en cuenta que el bilingüismo es una cuestión de grado, pueden observarse las características de comportamiento bilingüe. En otras palabras, el uso de dos o más lenguas y su alternancia permite observar las interferencias y el cambio de código que son rasgos significativos en los individuos bilingües, y el objeto de estudio de muchos sociolingüistas. No obstante, tanto la competencia lingüística como la competencia comunicativa son principios fundamentales a la hora de definir los diferentes tipos de individuos bilingües.

\subsection{Tipos de Bilingüismo}

La primera distinción importante para establecer una tipología de bilingüismo es la que distingue el bilingüismo individual del bilingüismo social. El primero trata el bilingüismo desde el punto de vista de la psicolingüística, el segundo hace referencia a una comunidad donde hay presencia activa de dos o más lenguas, es decir, es el objeto de estudio de la sociolingüística (Abelló Contesse \& Ehlers 2010: 10).

\section{Bilingüismo Individual}

Una de las clasificaciones del bilingüismo individual es la que tiene en cuenta la edad de adquisición de una segunda lengua. Teniendo en cuenta este parámetro, distinguimos, según Montrul (2013: 9-13), dos tipos de individuo bilingüe:

1. Bilingüe temprano: comprende la adquisición de una segunda lengua durante la infancia. En este caso, se ha de hacer una distinción entre un bilingüe simultáneo y uno secuencial. La diferencia se halla en que en primer caso, el individuo aprende dos lenguas desde el nacimiento. En segundo caso, primero aprende una lengua y posteriormente la otra.

2. Bilingüe tardio: hace referencia a la adquisición de una segunda lengua a partir de los 12 años, por lo tanto, estamos ante un bilingüe secuencial. 
Por otra parte, Montrul (2013) menciona la distinción entre bilingüismo compuesto y bilingüismo coordinado. Esta distinción se basa en la organización cognitiva; en concreto, en las representaciones semánticas de las palabras:

- El bilingüe compuesto tiene solo una representación semántica de la palabra, razón por la cual este tipo de bilingües suelen cometer errores léxicos.

- El bilingüe coordinado tiene dos representaciones distintas, es decir, para un mismo concepto tendría dos representaciones correspondientes a cada una de las lenguas y, por consiguiente, sabría utilizar las palabras en su contexto adecuado.

Respecto a las tipologías de bilingüismo que tienen como la base la capacidad comunicativa, hay muchas propuestas basadas tanto en el uso de una segunda lengua como en la capacidad comunicativa. Una buena clasificación de los distintos tipos de bilingüismo es la que proporcionan Christian Abelló Contesse y Christoph Ehlers (2010: 10-14) y que nosotros resumimos a continuación:

- Bilingüismo activo/productivo versus bilingüismo pasivo/receptivo. Se basa en las habilidades productivas y receptivas. En el primero de los casos el hablante es capaz de hablar, mientras que en el segundo estamos ante un bilingüe del tipo 'entiendo pero no hablo'.

- Bilingüismo aditivo versus bilingüismo sustractivo. Ambos términos se refieren al efecto que el bilingüismo tiene en el hablante a medio y largo plazo. El primer término hace referencia a una lengua complementaria. En el bilingüismo sustractivo, la lengua adquirida en un primer momento como adicional/complementaria reemplaza a la primera con el tiempo. Un ejemplo que puede ilustrar este tipo de bilingüismo es el caso de los inmigrantes en USA que reemplazan, en algunos casos, su primera lengua por el inglés, llegando incluso al monolingüismo en inglés.

- Bilingüismo ascendente versus bilingüismo recesivo. El primer término apunta a un individuo cuya capacidad comunicativa en una segunda lengua evoluciona favorablemente, ya que su situación le permite practicar la segunda lengua. El segundo término hace referencia a la situación contraria; el hablante bilingüe va perdiendo su habilidad comunicativa en una segunda lengua por falta de práctica y comienza a experimentar dificultades en la expresión y/o comprensión. 
- Bilingüismo desequilibrado (asimétrico) versus bilingüismo equilibrado (ambilingüismo/equilingüismo). Los dos términos se refieren al manejo de una segunda lengua. El bilingüe equilibrado es el bilingüe $i d e a l$, ya que posee la capacidad comunicativa de un nativo, por tanto, se ajustaría al prototipo de la definición de Bloomfield (1933). El bilingüe desequilibrado hace referencia a un individuo con dominio desigual de dos o más lenguas, con el manejo de una lengua predominante. Este es el caso de la gran mayoría de las personas bilingües.

- Bilingüismo fortuito/circunstancial versus bilingüismo optativo/electivo. En el primer tipo de bilingüismo nos encontramos con un individuo que, por circunstancias de la vida y sin alternativa de elección, adquiere una segunda lengua. El segundo término se refiere a la alternativa de la elección de la lengua adicional que se quiere aprender. El caso más ilustrativo es el aprendizaje de segundas lenguas en el ámbito escolar.

- Bilingüismo funcional. Estamos ante el bilingüismo que tiene que ver con el manejo de dos lenguas con grado de fluidez y precisión distintas dependiendo de los interlocutores y del contexto en el que se usa la segunda lengua. Un ejemplo sería el aprendizaje de la lengua adicional en la escuela: el grado de fluidez y precisión del estudiante dependerá del plan escolar y del profesor, su interlocutor.

- Bilingüismo incipiente. Engloba hablantes que poseen la mínima competencia en una segunda lengua; es decir, la mínima exigencia respecto al dominio de la lengua para que pueda hablarse de un individuo bilingüe. En este grupo entrarían turistas que dominan algunas frases en una segunda lengua (Baker 2006: 8). Este tipo de bilingüismo se incluye dentro de la categoría del bilingüismo mínimo descrita a continuación.

- Bilingüismo mínimo versus bilingüismo máximo. El primer término hace referencia a un individuo que tiene solo nociones básicas de actuación en una segunda lengua, por el contrario, el bilingüe máximo tiene un nivel de uso de la segunda lengua muy similar al del hablante nativo.

- Bilingüismo familiar. Hace referencia a lenguas utilizadas en un ámbito social reducido. Es decir, el niño está en contacto con más de una lengua en el ámbito familiar. Algunos estudios tienen en cuenta el patrón 'una persona, una lengua'; la madre utiliza una lengua y el padre la otra.

- Bilingüismo educativo o enseñanza bilingüe. Este es el caso de niños que asisten a clases de educación bilingüe. Se trata de los planes escolares que 
ofrecen el aprendizaje de segundas lenguas. Es necesario poner de relieve que no todos los planes de este tipo de educación ofrecen el mismo nivel de actuación que un individuo puede adquirir. También hay que tener en cuenta que, en muchas ocasiones, los objetivos de los mismos estudiantes respecto al dominio deseado que quieren alcanzar son diferentes.

Los diferentes tipos de individuos bilingües mencionados son los más comunes. En muchas ocasiones, una minoría lingüística puede clasificarse bajo un mismo tipo de bilingüismo, ya que, por norma general, las circunstancias contextuales y personales que poseen los miembros de estas minorías presentan rasgos comunes (por ejemplo, los inmigrantes en Estados Unidos).

\section{Bilingüismo Social}

En el apartado anterior hemos definido y caracterizado el bilingüismo a nivel individual. Ahora bien, como afirma Montrul (2013):

No es posible abordar el estudio del individuo bilingüe sin tener en cuenta cómo se usan las lenguas en el contextos social en el que vive. Es decir, dentro de una sociedad, el grado y el tipo de bilingüismo de un hablante en particular están estrechamente vinculados tanto a su contexto sociopolítico como a la funcionalidad de las lengua en ese contexto (Montrul 2013: 26).

Hablamos de bilingüismo social o sociedad bilingüe cuando un grupo de individuos forman una comunidad dentro de un espacio definido. En una sociedad bilingüe, los miembros de los grupos lingüísticos que comparten un mismo territorio mantienen una compleja red de relaciones que se reflejan en el uso de las lenguas y sus funciones sociales, y el prestigio que se les concede (Siguán \& Mackey 1989: 44-45). Hay que tener en cuenta que para hablar de sociedad bilingüe no es necesario que cada uno de los individuos que la componen sea bilingüe, es suficiente con que las dos o más lenguas coexistan en el territorio y con que algunos hablantes usen una lengua, otros utilicen la otra y algunos (o muchos) puedan usar las dos (Montrul 2013: 26). En otras palabras, una sociedad bilingüe, o plurilingüe, es una sociedad en la que dos o más lenguas tienen algún tipo de vigencia social, lo cual significa que son usadas en determinadas situaciones de acuerdo con normas explícitas o implícitas (Siguán 2001: 32). Las formas de bilingüismo social más ampliamente 
aceptadas son las que presentan Appel y Muysken (1996) (citado por Moreno Fernández 2009: 211-212). Estos lingüistas se refieren a las tres situaciones de bilingüismo social que resumimos a continuación:

1. Situación 1: cada una de las lenguas es hablada por un grupo diferente; se trata de grupos monolingües que, al yuxtaponerse, constituyen una comunidad bilingüe y que requieren la intervención de algunos individuos bilingües para comunicarse entre sí.

2. Situación 2: todos o casi todos los hablantes son bilingües.

3. Situación 3: coexistencia de un grupo monolingüe dominante desde una perspectiva sociológica y otro bilingüe, a menudo minoritario.

Lo que mejor caracteriza a una situación bilingüe es que las lenguas que coexisten poseen el mismo estatus de poder o de prestigio; es decir, una lengua está al lado de la otra, cumpliendo las mismas funciones (Ninyoles 1972; Siguán \& Mackey 1989), en todos los ámbitos que eso engloba: política, administración, educación, etc. Teniendo en cuenta esta característica, se nos ofrece un nuevo planteamiento, respecto al uso del término bilingüismo, que Fishman (1972) ha introducido para realizar sus trabajos sobre las situaciones del contacto de dos o varias lenguas en un territorio. Este lingüista reserva, en principio, el concepto de bilingüismo para describir la existencia de dos lenguas en un individuo, y utiliza el concepto de diglosia cuando se habla del uso de dos lenguas en una sociedad determinada (Baker 2006: 69). Ahora bien, como afirma Moreno Fernández (2009: 229), cuando Fishman establece los tipos de relación que podrían mantener bilingüismo y diglosia "trasforma el concepto de bilingüismo en un atributo social, tan social como la diglosia, y lo define como el dominio por parte de una sociedad, tanto de (una lengua) A como (de una lengua) B; cuando se produce una distribución funcional de A y B se estaría ante un caso de diglosia."

\subsection{Diglosia}

En general, en las sociedades donde coexisten dos lenguas pueden observarse circunstancias en las que cada lengua se emplea para una función determinada; una lengua suele emplearse en situaciones formales mientras que la otra se utiliza en circunstancias informales. Cuando se produce esta distribución funcional de las lenguas en determinado territorio estamos ante una situación de diglosia. 
El término diglosia fue acuñado por Charles Ferguson quien lo utilizó por primera vez en la revista Word en 1959. Según Ferguson (1959), la diglosia define comunidades lingüísticas en las que los hablantes usan dos o más variedades lingüísticas para fines o funciones diferentes. Se trata, por tanto, de situaciones en las que se tiende a utilizar dos lenguas; una lengua dominante, la variedad A; y otra, no dominante, la variedad B. Ferguson (1959) basa su análisis en la situación lingüística del árabe, del griego moderno, del alemán suizo y del criollo haitiano. Establece una serie de requisitos que aparecen en las situaciones diglósicas y que giran en torno a los siguientes factores:

1. la función de cada variedad;

2. el prestigio de la variedad;

3. la herencia literaria;

4. la adquisición;

5. la estandarización;

6. la estabilidad;

7. la gramática;

8. el lexicón;

9. la fonología.

De entre todos estos factores, la función es el criterio crucial para establecer una situación diglósica. A partir de ahí, Ferguson (1959) analiza las diferentes situaciones de la vida cotidiana para observar la función de las variedades. La descripción del autor se basa en la distinción entre la lengua mayoritaria, que él denomina High variety $(\mathrm{H})$, y la minoritaria, Low variety $(\mathrm{L})$. A partir de aquí establece ámbitos según la función de $\mathrm{H}$ y de $\mathrm{L}$ dentro de un determinado territorio, como refleja la Figura 1 (mencionada en Baker 2006).

Por su parte, Fishman (1972) definió la diglosia como un fenómeno que comprende la existencia de dos lenguas dentro de un área geográfica. Es decir, a diferencia de Ferguson (1959), quien consideraba que una situación de diglosia solo podía darse entre dos variedades de una misma lengua, Fishman amplía la definición y aplica el término diglosia a circunstancias en las que coexisten dos lenguas que pertenecen a familias lingüísticas diferentes. La definición de Fishman (1972) mantiene la idea de que cada una de las lenguas se utiliza para funciones diferentes. Fishman (1989: 184-189) distingue cuatro tipos de relaciones entre bilingüismo y diglosia: 


\begin{tabular}{|l|l|c|c|}
\hline \multicolumn{2}{|l|}{ Context } & $\begin{array}{c}\text { Majority } \\
\text { Language }(H)\end{array}$ & $\begin{array}{c}\text { Minority } \\
\text { Language }(L)\end{array}$ \\
\hline 1. & The home and family & & $x$ \\
\hline 2. & Schooling & $x$ & \\
\hline 3. & Mass Media and WWW & $x$ & \\
\hline 4. & Business and commerce & $x$ & \\
\hline 5. & Social and cultural activity in the community & & $x$ \\
\hline 6. & Correspondence with relatives and friends & & $x$ \\
\hline 7. & Correspondence with government departments & $x$ & \\
\hline 8. & Religious activity & & $x$ \\
\hline
\end{tabular}

Fig. 1. Diglosia, Ferguson (1959).

1. Bilingüismo con diglosia. "This is a societal arrangement in which individual bilingualism is not only widespread but institutionally buttressed" (Fishman 1989: 185), es decir, en este tipo de sociedad los miembros son capaces de utilizar las dos lenguas. La lengua A se emplea en las instituciones públicas (educación, gobierno, etc.) y la B en el ámbito familiar, vecindario, amistades, etc.

2. Bilingüismo sin diglosia. Se trata de aquellas situaciones bilingües que no duran o no van más allá de tres generaciones. Como resultado, la lengua más fuerte acaba imponiéndose y gana terreno. Este es el caso de los inmigrantes que a partir de la tercera generación suelen convertirse en monolingües de la lengua dominante en el territorio de destino, en otras palabras, la primera lengua es sustituida por la segunda (por ejemplo, la situación de los inmigrantes en Estados Unidos).

3. Diglosia sin bilingüismo. En este contexto existen dos lenguas en la misma área geográfica: una es utilizada por un grupo de hablantes y la otra por el otro. Hay que reconocer que estamos ante un caso hipotético, sin ejemplos que señalar en la actualidad; este tipo de circunstancias caracteriza las situaciones coloniales en las que el grupo con poder utiliza solo la lengua A, y el resto de la población solo la lengua B. Este podría ser el caso del inglés hablado por la élite en la India y las lenguas indígenas habladas por el resto de la población (Baker 2006: 70).

4. Ni diglosia ni bilingüismo. Estamos ante el caso de las sociedades con varios grupos lingüísticos diferentes que bajo la presión social van cambiando a monolingües en la lengua dominante. Para ejemplificar esta situación, Fishman expone el caso de Corea, Yemen, Cuba o Noruega. Estos países, por un lado, han experimentado poca inmigración y, por el otro, tampoco 
tenían un número excesivo de minorías indígenas; razón por la cual muchos de ellos han pasado por la sustitución de su lengua por la dominante (Fishman 1989: 188).

A partir de estas cuatro situaciones, Fishman considera que la diglosia con o sin bilingüismo tiende a proporcionar una lengua relativamente estable y duradera (Fishman 1989: 187). No obstante, con la creciente comunicación, movilidad social y globalización, el contacto de lenguas es un fenómeno creciente y, por lo tanto, la estabilidad expuesta por Fishman es un fenómeno raro en el mundo globalizado (Baker 2006: 72). Evidentemente, con el paso de los años y con las modificaciones que sufre y ha sufrido la sociedad, sería necesario redefinir el término de diglosia. Por un lado, la definición de Ferguson (1959) no resulta válida en la actualidad ya que en la mayoría de las situaciones de contacto de lingüístico entran en contacto lenguas que pertenecen a familias lingüísticas diferentes. Por otro lado, aunque la definición de Fishman (1972) es más flexible, también presenta problemas ya que, como he mencionado anteriormente, el contacto de lenguas que puede observarse en la actualidad, no presenta ninguna estabilidad y no tiene un espacio temporal duradero. A pesar de los problemas que puedan plantear estas definiciones a la hora de analizar situaciones actuales de contacto de lenguas, evidentemente los factores tenidos en cuenta por estos lingüistas garantizan la posibilidad de realizar un estudio sociolingüístico del contacto lingüístico en el que conceptos como prestigio, identidad o actitud resultan fundamentales.

\section{Prestigio, Actitud e Identidad}

El objetivo del presente trabajo es analizar la situación de la lengua española y su posible futuro en los Estados Unidos, por lo tanto, hay que partir de la perspectiva de la macrosociolingüística, lo que conlleva tener en cuenta los conceptos de prestigio, actitud e identidad, ya que la lengua es una de las señas que determina y caracteriza al individuo. A continuación nos ocupamos de estos conceptos que constituyen el punto de partida para aclarar el curso que sigue el español en EE.UU.

\subsection{Prestigio}

Para definir la noción de prestigio podemos partir de la definición que propone el DRAE (www.rae.es) "realce, estimación, renombre, buen crédito", "ascendi- 
ente, influencia, autoridad". Como puede observarse, el concepto de prestigio hace una clara referencia al valor que se otorga a un individuo o a una unidad, a través de una influencia exterior, con el resultado de superioridad en alguno de los rasgos que se tienen en cuenta y que son los que determinan la conducta de los demás individuos.

Desde el punto de vista de la sociología, el prestigio de un individuo se puede fijar a partir de las cuatro variables establecidas por Hans Gerth y Charles Wright Mills (Lucas Marín 1989): 1) la ocupación; 2) la clase; 3) el estatus; y 4) el poder. Estas variables están ligadas entre sí y parten de la ocupación; es decir, de los ingresos económicos de un individuo, ya que estos son los que determinan la clase, el estatus y, en primera estancia, el poder. En otras palabras, estamos ante variables condicionadas socialmente y ante las que se genera la presión social entre la población.

Si nos ocupamos de las lenguas, la aplicación de la definición del DRAE lleva al concepto de prestigio lingüistico que es "valor que el hombre otorga a una lengua en relación de ascenso laboral y social", es decir, las cuatro variables mencionadas anteriormente juegan un papel importante respecto al estatus que las personas otorgan a las lenguas. En la misma línea se sitúan las consideraciones de Weinreich (1953) quien considera que hay que restringir el prestigio al valor de una lengua en el ascenso social. A nivel social, la lengua con prestigio suele ser la utilizada por los grupos lingüísticos con poder. Por el contrario, la lengua de los grupos minoritarios (por ejemplo las lenguas de los inmigrantes) no posee el mismo prestigio que la lengua del país de acogida.

El prestigio está relacionado con el poder y, por consiguiente, los miembros que pertenecen a los grupos con lengua sin prestigio suelen optar por la adaptación a la lengua dominante, con el objetivo de adquirir mayor estatus. De modo que, el prestigio lingüístico está estrechamente relacionado con la sustitución lingüistica; es decir, la renuncia a la lengua materna. Es fácil determinar qué lengua goza de mayor prestigio, ya que suele ser la lengua con una larga historia literaria, y está protegida por la sociedad y las instituciones que la representan. Consecuentemente, la lengua con prestigio es la que se utiliza en los ámbitos públicos (administración, educación, etc.) y la lengua con menos prestigio es la utilizada en el ámbito privado (familia, vecindario, amistades, etc.). 


\subsection{Identidad y Actitud}

Para analizar cualquier situación lingüística en un territorio hay que tener en cuenta tanto la lengua como los individuos que la utilizan; es decir, hay que prestar atención a los aspectos sociales y psicológicos presentes entre los miembros de una población, más todavía si el espacio es compartido por personas de diferente procedencia, ya que estos factores son los que determinan e influyen en todo lo que tiene que ver con las lenguas que están en contacto.

Cualquier individuo, sea cual sea su procedencia, tiene la subjetiva intuición de que pertenece a un grupo y a una categoría de personas. Pertenecer a un grupo conlleva ciertas consecuencias (Silverstain 2003), que, a su vez, se hacen evidentes en el ámbito de la lengua, que es nuestra identidad lingüística. Los conceptos identidad e identidad lingüistica son definidos por BustamanteLópez (2008):

I will define identity as how we represent ourselves in the social world and linguistic identities as the language we employ to represent ourselves (Bustamante-López 2008: 279).

Tener presente esta relación entre los dos conceptos es primordial para poder entender que, a partir de estos dos componentes, los diferentes grupos lingüísticos manifiestan los prejuicios respecto a las diferentes lenguas. En otras palabras, en cada sociedad los miembros que la componen revelan y expresan su postura respecto a las diferentes lenguas, ya sea consecuencia del carácter histórico o del sociopolítico; es decir, estamos ante la actitud lingüistica de los sujetos.

La actitud hacia una lengua, tanto de los hablantes de una comunidad como de los órganos políticos, es un componente que juega un papel importante a la hora de realizar un estudio sociolingüístico, porque puede determinar de manera positiva, pero también negativa, la lengua propia y los hablantes que la utilizan. Encontramos diferentes definiciones e intentos de describir el concepto de actitud lingüistica. Baker (1992: 10) considera que la actitud "es un constructo hipotético empleado para explicar la dirección y la persistencia de la conducta humana." Andrew Lynch y Carol Klee (2005) se basan en la definición de las actitudes -en lo que respecta a la lenguadel Círculo de Bajtín y afirman que: "las actitudes lingüísticas son, pues, una manifestación de actitudes sociales, entramando lo verbal con lo sociopolítico y lo económico" (Lynch \& Klee 2005: 273). 
Los estudios que se ocupan de las actitudes lingüísticas se centran en el 'diagnóstico social' de una variedad de la lengua. Analizan si el uso de una lengua conduce a asociar al hablante con un grupo social particular, pero también se interesan por la actitud de los propios hablantes hacia su lengua y, por lo tanto, por su valor en la comunidad dominante. No obstante, hay que tener presente una clara distinción entre actitudes e ideologias: de las primeras el hablante no es consciente; las segundas representan los intereses que se centran en los valores que los dos grupos dan a la lengua, aunque el énfasis se pone en el ámbito político donde están expuestas las diferencias entre las lenguas o entre las variedades de una lengua (Myers-Scotton 2006). A partir de lo dicho, puede afirmarse que las actitudes se manifiestan en las distintas ideologías, y, por eso, son uno de los componentes más importantes a la hora de determinar el mantenimiento, la restauración, el decaimiento o la muerte de lenguas, y, por supuesto, determinan los proyectos de las planificaciones lingüísticas (Fasold 1996; Baker 2006; Myers-Scotton 2006), y eso afecta a la educación bilingüe, ya que su implementación y su apoyo por parte de los órganos políticos es una de las formas más seguras de mantener una lengua viva y vigente al lado de la lengua nacional, en palabras de Baker (1992):

In life of language, attitudes to that language appear to be important in language restoration, preservation, decay or death. If community is grossly unfavorable to bilingual education or the imposition of 'common' national language is attempted, language implementation is unlikely to be successful (Baker 1992: 9).

Por esta razón, "el estatus, valor y la importancia de una lengua pueden medirse a partir de las actitudes hacia a la determinada lengua" (Baker 1992: 9). Otros autores, como Fasold (1996), añaden que "a menudo, sin embargo, la definición de actitud lingüística se amplía para abarcar las actitudes hacia los hablantes de una lengua o dialecto particulares" (Fasold 1996: 231). Por tanto, las actitudes lingüísticas son el reflejo de las actitudes hacia los propios hablantes de un grupo étnico. El conjunto de las actitudes y de las ideologías lingüísticas tiene una gran influencia en los territorios donde hay una situación bilingüe, ya que éste determina el mantenimiento o la sustitución lingüísticos.

\subsection{Mantenimiento y Sustitución Lingüísticos}

Como he mencionado anteriormente, en las sociedades en las que coexisten diferentes grupos minoritarios, se puede observar la relación entre la lengua 
dominante con prestigio y la lengua sin prestigio de los grupos lingüísticos minoritarios. En muchas ocasiones, la presión social obliga a los miembros de los grupos minoritarios a adoptar la lengua dominante llevándolos hacia el monolingüismo. Por tanto, por sustitución lingüistica se entiende:

La redistribución de variedades lingüísticas en determinados ámbitos. Si la sustitución se ejerce a favor de la lengua mayoritaria, esta lengua parece ir conquistando ámbito tras ámbito por medio del estado intermedio de uso bilingüe (Appel \& Muysken 1996: 63).

Por supuesto, la importancia principal la tiene la transmisión intergeneracional, pero también hay varios agentes externos, que son el resultado de la influencia del contexto social. Por consiguiente, pueden fijarse factores que determinan la situación de las lenguas en contacto, como señalan Appel y Muysken (1996). Para ellos, el estatus económico es el más relevante y va estrechamente ligado al estatus social. Asimismo, el estatus social y la lengua presentan una relación de gran importancia, ya que, como varios estudios sociolingüísticos han demostrado, el uso de una determinada lengua o de una variedad de una lengua es la característica principal de una clase social o de un grupo étnico determinados; es la 'marca' de los miembros de un grupo lingüístico, y no es de sorprender que estos se enfrenten a la autoevaluación que puede ser positiva pero también negativa, más si se trata de un grupo minoritario que percibe su inferioridad lingüística frente al grupo dominante.

Otro de los factores que puede ser relevante en las comunidades bilingües es el estatus lingüistico, pero, como Appel y Muysken (1996) afirman, "es preciso recordar que debemos distinguir el estatus dentro de una comunidad del estatus fuera de la comunidad" (Appel \& Muysken 1996: 54). Este sería el caso del español en los Estados Unidos: es una lengua de prestigio a nivel global, pero también es una lengua sin prestigio en la Unión.

Otro factor relevante a la hora asegurar el mantenimiento de una lengua es el apoyo institucional; es decir, la planificación lingüística por parte del estado y su aplicación.

Por último, no hay que olvidarse de los factores demográficos. Estos hacen referencia al número de un grupo lingüístico y a su distribución demográfica, ya que cuanto mayor es el número de hablantes de una lengua en un territorio determinado, más probabilidades existen de que se mantenga la lengua minoritaria. 


\subsection{Comunidad de Habla}

Todos los conceptos mencionados hasta ahora -prestigio, identidad y actitudes lingüísticas- son fenómenos que afectan positivamente y/o negativamente a los miembros de una comunidad lingüística y, por supuesto, a la lengua que los identifica. Esta idea nos lleva a un concepto clave en sociolingüística: $c o-$ munidad de habla. Este concepto se define de maneras diversas. Para Salzmann (1998), una comunidad de habla está formada por "All those who share specifics rules for speaking and interpreting speech and at least one speech variety belong to a speech community" (Salzmann 1998: 217). Montrul (2013) considera que la característica principal de una comunidad de hablantes o comunidad lingüística es que "los miembros comparten una lengua y una variedad de lengua en particular y comparten las normas lingüísticas que rigen el uso apropiado de esa lengua o una variedad en distintos contextos sociales" (Montrul 2013: 27). Saussure, por su parte, considera que la lengua constituye el lazo social y:

Es un tesoro depositado por la práctica del habla en los sujetos que pertenecen a una misma comunidad, un sistema gramatical virtualmente existente en cada cerebro, o, más exactamente, en los cerebros de un conjunto de individuos, pues la lengua no está completa en ninguno, no existe perfectamente más que en la masa (Saussure 1916: $57)$.

Como puede observarse, los diversos autores coinciden en que la comunidad de habla es el conjunto de individuos que comparten una lengua y su uso. No obstante, actualmente es difícil definir una comunidad de habla, ya que el fenómeno de la globalización impide delimitar sus fronteras debido al constante contacto de lenguas y a una población formada por diversos grupos lingüísticos, que cuentan con un número variable de miembros en constante movimiento. Por tanto, para poder definir el concepto tratado y realizar un estudio de la situación lingüística en un territorio determinado es necesario tener en cuenta el fenómeno de la globalización, que influye directamente tanto sobre la lengua como sobre su uso. Desde este punto de vista, podríamos definir la globalización y su relación con lenguas de la siguiente manera:

El concepto de globalización comprende un sistema a nivel mundial de interconexiones sociales, políticas y culturales. Eso está especialmente asociado con el impacto económico. Podríamos decir, respecto 
al lenguaje, que las decisiones sobre qué lengua hablar, con quién y cómo son también decididas por alguien para sus propósitos (MarMolinero 2009: 11).

Desde este punto de vista, hay que intentar redefinir el concepto de comunidad de habla para adaptarlo a las circunstancias actuales. En esta línea, Andrew Lynch (2013) considera que las definiciones de los clásicos sobre comunidad de habla no son aplicables en la era global y, por esta razón, propone lo siguiente:

La comunidad de habla en la época global adquiere, en términos conceptuales, más rasgos del tipo que tal vez asociaríamos con las llamadas comunidades profesionales, 'mundos' o 'ámbitos', por ejemplo, el mundo académico, el mundo de los negocios, el ámbito legal, el ámbito de la psiquiatría, etc., y menos características del tipo que asociaríamos con un vecindario, una ciudad, o una región, los cuales son, por necesidad, delimitados por el espacio físico (Lynch 2013: 69).

La propuesta de Lynch (2013) se relaciona de manera clara con el concepto de comunidad de práctica utilizado por algunos sociolingüistas. Díaz Campos (2014) define la comunidad de práctica como:

Un grupo mucho más pequeño de personas (en comparación con la comunidad de habla) que participan en una actividad común. Eckert (2009: 35) argumenta que la comunidad de práctica es un grupo de individuos que se juntan en función de un propósito común y que en el desarrollo de ese objetivo común comparten maneras de hacer ciertas cosas, maneras de hablar, creencias y valores (Díaz Campos 2014: 26).

La redefinición de Lynch (2013) o el concepto de comunidad de práctica nos permite centrar nuestro interés en los núcleos concretos que están relacionados con el uso de una lengua determinada por las reglas sociopolíticas. Estas reglas ejercen una verdadera presión sobre los hablantes de un territorio determinado a la hora de elegir la lengua de uso.

De lo dicho se sigue que un estudio de la situación lingüística en un determinado territorio en la era de la globalización no puede basarse solo en los principios que tradicionalmente se han utilizado para estudiar las situaciones de bilingüismo, principios que se basaban sobre todo en las costumbres de uso 
de una lengua por parte de los hablantes de un espacio determinado. Actualmente, para realizar un análisis adecuado no es suficiente con analizar una comunidad de habla a partir de datos sobre las lenguas utilizadas en casa, en el vecindario, en el barrio ... o cualquier otra idea basada en la definición clásica de comunidad de habla. Evidentemente, ese tipo de datos es útil para acercarse al uso de la lengua de un grupo determinado, pero no para analizar una situación bilingüe y para determinar en qué situación se encuentran o se podrían encontrar las lenguas en contacto en un determinado territorio. Para el tipo de análisis que queremos realizar, resulta mucho más adecuado utilizar la redefinición del concepto de comunidad de habla propuesta por Lynch o el concepto de comunidad de práctica propuesto por algunos estudios. Un ejemplo de este tipo de análisis es el realizado por Andrew Lynch (2013) quien estudió la actitud de los estudiantes hacia el español en Florida. Es decir, el centro de atención de este estudioso fue el ámbito académico que puede constituir un ejemplo de comunidad de habla -o comunidad de práctica- en el mundo globalizado. Este tipo de análisis resulta adecuado para un estudio sociolingüístico como afirma Mar-Molinero (2009) quien considera que:

Para poder tratar la difusión y propagación de una lengua y la globalización hay que centrar la atención en el análisis dentro del área que comprende "contacto de las lenguas, competición y política". También el papel importante lo juega la planificación lingüística, abierta y encubierta, que difunden la ideología y regulación que guía el uso de la lengua en la sociedad (Mar-Molinero 2009: 9).

Teniendo en cuenta lo dicho, en este trabajo se entenderá el concepto de comunidad de habla desde la perspectiva de Andrew Lynch. A partir de esa definición, centraremos nuestra atención en los ámbitos relacionados con la planificación lingüística de un estado determinado.

A partir de aquí, el presente trabajo tiene como base dos análisis: el primero se fija en cómo las políticas lingüísticas afectan al terreno de las instituciones públicas en EE.UU.:

Eso se manifiesta en el empleo de la lengua en la administración pública, en el ámbito jurídico, medios de comunicación y, particularmente, en el sistema educativo que es el fruto de las ideas y creencias respecto al repertorio de la lengua de la comunidad (Mar-Molinero 2009: 9). 
Y el segundo análisis tendrá en cuenta el uso de la lengua que hacen los hablantes del país, ya que los miembros de los distintos grupos lingüísticos son el reflejo de la actuación política adoptada en el ámbito relacionado con la lengua de la nación.

\section{Español en EE.UU.}

El español y su presencia en EE.UU. tienen una larga historia. Se remonta a los siglos XV y XVI con el descubrimiento, conquista y colonización del Nuevo Continente por parte de los españoles. La entrada de los primeros conquistadores anglosajones en el siglo XVII fue el primer paso para la lengua inglesa y su extensión por todo el continente norteamericano a lo largo de los siglos sucesivos. El siglo XIX fue muy significativo en lo que se refiere a la expansión de los EE.UU., y por tanto de su lengua, que fue guiada por la doctrina Manifest Destiny: una creencia según la cual tenían la divina misión de expandirse hacia el oeste del continente norteamericano hasta el Océano Pacífico. Esta doctrina profesaba la superioridad cultural y racial de los europeos blancos cuya misión era americanizar a los "incivilizados" no-europeos (Bhatia y Ritchie 2012). El Manifest Destiny servía como justificación para el desplazamiento de los no-europeos como resultado de la opresión y de las guerras con los indígenas y los pueblos mexicanos.

La guerra México-americana (1846-1848) terminó con el Tratado de Guadalupe de Hidalgo según el cual México tuvo que ceder la mitad de su territorio a los EE.UU. El territorio cedido comprende, actualmente, Texas, Nuevo México, Arizona, California, Nevada, Utah y una gran parte de Colorado (Bhatia y Ritchie 2012). Los mexicanos que no abandonaron estas tierras eran hispanohablantes y estaban obligados a aprender inglés, lengua que se había convertido en la lengua de instrucción en las escuelas y que se consideraba como la manera de civilizarlos, tal y como exigía la cultura anglosajona. Este es un ejemplo que explica el porqué de la presencia de la lengua española en el territorio estadounidense y que rebate las consideraciones aceptadas por muchos que, en la actualidad, consideran que el español es el resultado de las masivas olas de inmigración desde América latina hacia territorio estadounidense.

Un caso similar al de México fue la isla de Puerto Rico, que se convirtió en tierra de los EE.UU. con su victoria en la guerra española-americana en 1898. Como la población era hispanohablante, los nuevos dueños declararon en 1902 el español y el inglés como lenguas oficiales, aunque el inglés fue la 
lengua impuesta en ámbito educativo hasta 1930. Cien años después de la anexión de Puerto Rico a EE.UU., el español se ha convertido en la lengua de instrucción en las escuelas.

Junto a Puerto Rico, Nuevo México es uno de los estados de la Unión que presenta una particularidad con respecto al resto de los Estados en el ámbito de la lengua, ya que el español es la lengua cooficial en el territorio y está presente en el sistema educativo. Esto convierte a Nuevo México en el único estado de la Unión bilingüe constitucionalmente, "aunque de forma limitada" (Consejería de Educación, Embajada de España en Estados Unidos 2012-2013: 8).

Los ejemplos expuestos demuestran que la lengua española ha estado presente en Norteamérica desde los primeros pasos de los conquistadores españoles. En todo caso, no hay que olvidar la propagación actual del español ni los grandes esfuerzos que realizan las instituciones políticas españolas para promocionar nuestro idioma, su historia y su cultura no solo entre la comunidad latina en territorio estadounidense, sino también entre los anglosajones del país que cada vez tienen más interés por aprender el idioma español.

La lengua española cuenta con el privilegio de estar convirtiéndose en una lengua franca debido, en parte, a la importancia que están ganando los países hispanohablantes en ámbito económico. Un papel fundamental es el desempeñado por la RAE cuyos estatutos vigentes, aprobados en 1993, establecen como objetivo fundamental de la Academia: "Velar por que la lengua española, en su continua adaptación a las necesidades de los hablantes, no quiebre su esencial unidad"(www.rae.es). Este compromiso se ha plasmado en la denominada política lingüística panhispánica, compartida con las otras veintiuna corporaciones que forman parte de la Asociación de Academias de la Lengua Española (ASALE), creada en México en 1951.

ASALE está formada por 22 academias de las que la más joven es la Academia norteamericana de la lengua española (ANLE) fundada en 1973. Este órgano es el apoyo imprescindible en la difusión de la lengua española tanto entre los norteamericanos como entre la población hispana de los EE.UU.

Además de la RAE y ANLE, no hay que olvidar la importancia del Instituto Cervantes, una institución pública creada en España en 1991 "para la promoción y la enseñanza de la lengua española y de las lenguas cooficiales y para la difusión de la cultura española e hispanoamericana" (www.cervantes.es). 
Uno de los objetivos del Instituto es formar buenos profesionales de la enseñanza del idioma para poder difundir y promover el español alrededor del mundo. En la actualidad, cuenta con 86 academias, de las cuales 5 se encuentran en los Estados Unidos, en concreto, en Albuquerque, Boston, Nueva York, Chicago y Seattle. Como afirma la institución, el crecimiento de los alumnos interesados en aprender la lengua española es de un $8 \%$ anual. Esto significa que la lengua española está en pleno apogeo en EE.UU., razón por la cual se reafirma el impacto que tiene entre la población norteamericana. Hay que mencionar también la reciente creación del Observatorio de la lengua española y las culturas hispánicas en los Estados Unidos en colaboración con la Universidad de Harvard, cuyo objetivo es:

Crear un centro que sirva como punto de referencia internacional para el estudio, el análisis prospectivo y diagnóstico de la situación de la lengua española en los Estados Unidos, con especial atención a su evolución social, cultural y lingüística, su uso por los hablantes del español, incluidas las minorías, pero no exclusivamente, y su coexistencia con otras lenguas ${ }^{2}$.

Otro gran factor responsable de la presencia del español en EE.UU. es la inmigración procedente de los países latinoamericanos. Los inmigrantes son una fuente para la divulgación del castellano y de la cultura española. La situación de la población latina en EE.UU. ilustra el impacto de las bases y los agentes de la globalización en el cambio de la lengua en la sociedad, mientras la planificación lingüística del gobierno español y particularmente del Instituto Cervantes, refuerza las reclamaciones del imperialismo lingüístico europeo en la difusión de una lengua global: el español (Mar-Molinero 2009).

EE.UU. es, desde hace tiempo, destino de masivas avalanchas de inmigrantes que debido a las precarias condiciones de vida que les ofrecen sus países de origen se ven obligados a emigrar. En 1945, la población de EE.UU. estaba compuesta por un $87 \%$ de blancos, un $10 \%$ de negros, un $2,3 \%$ de hispanos y un $0,5 \%$ de asiáticos. Las proyecciones para el año 2050 estiman que, en ese año, el 52,8\% de la población será blanca, el 13,6\% será negra, el $24,5 \%$ de origen hispano y el $8,3 \%$ procedentes de Asia (Suárez-Orozco \& Suárez Orozco 2001).

${ }^{2}$ http://cervantesobservatorio.fas.harvard.edu/es 
La primera gran oleada de inmigrantes data de 1901 y se prolonga hasta 1910. La segunda se produjo en los años 60 y 80 del siglo XX (Lynch 2013). A pesar de que, los inmigrantes procedían de diferentes lugares del mundo, la gran mayoría era de origen latinoamericano, principalmente mexicano. En 1986, el gobierno federal aprobó una amnistía para los indocumentados que habían entrado en la Unión antes del 1982 y, de esta manera, se convirtieron en inmigrantes provisionales. El objetivo real de esta ley federal era reducir la inmigración ilegal, razón por la cual el gobierno reforzó las patrullas en las fronteras. No obstante, el resultado no fue el esperado y los ilegales siguieron entrando en el territorio. Las cosas cambiaron con la tragedia de 11 septiembre de 2001 y la inmigración se convirtió en una cuestión de seguridad.

Esta decisión afectó principalmente a los musulmanes y mexicanos. El gobierno cambió las políticas migratorias y a partir de este año, aumentaron las deportaciones de los ilegales, haciendo todo ello que el porcentaje de los nuevos ilegales empezara a disminuir, como demuestra la Figura $2^{3}$.

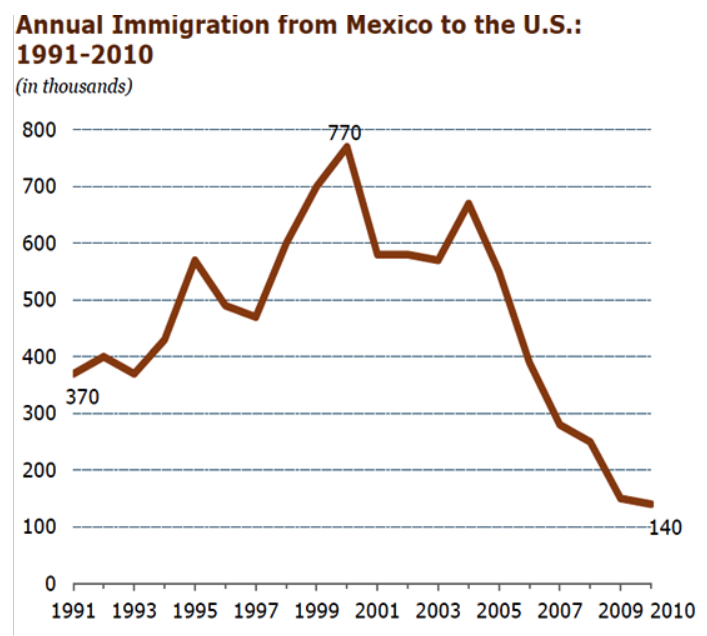

Fig. 2. Inmigración de México a EE.UU. Años 1991-2010.

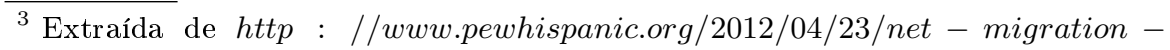
from - mexico - falls - to - zero - and - perhaps - less /
} 
Actualmente, según el Censo 2012 publicado por American FactFinder, en los Estados Unidos hay 40,8 millones de personas nacidas fuera de la Unión, de los que $52 \%$ son los llegados de América Latina. De estos, tan solo el $7 \%$ entró después del año 2010. Este dato hay que tenerlo en cuenta, ya que las primeras generaciones de inmigrantes son la clave para la transmisión de su lengua a las generaciones posteriores.

Respecto a las lenguas, la inmigración es la clave para entender por qué EE.UU. presenta un gran número de grupos lingüísticos diferentes con sus respectivas lenguas. Actualmente, según el Censo 2000 de la Modern Language Association $^{4}$, en el territorio de Estados Unidos hay una gran variedad de lenguas distintas al inglés, que en total forman el 19,62\%, es decir el otro $80,38 \%$ lo forman los hablantes de inglés. Del 19,62\%, el español es hablado por un $62,13 \%$, lo que significa que el español representa la segunda lengua más hablada de los EE.UU. Este hecho no es sorprendente si tenemos en cuenta que el número de los hablantes de origen hispano está aumentando año tras año debido a la alta natalidad registrada en la comunidad latina. La mayor concentración de la población hispanohablante se encuentra en el Suroeste del país, en Florida y en Nueva York.

Como puede observarse en la Figura 3, extraída del formato digital del periódico Prensa Libre ${ }^{5}$, la población de habla hispana se encuentra a lo largo de la frontera de los EE.UU. con México. Respecto al aumento de la población en su totalidad puede observarse un crecimiento considerable.

La población hispana representa un total del 12,5\% (35.305.818) de la población estadounidense. El grupo mayoritario es de origen mexicano $(7,3 \%)$ seguido por los puertorriqueños $(1,2 \%)$ y los cubanos $(0,4 \%)$. En 2010, los hispanos alcanzaron un $16,3 \%$ con 50.477 .594 de personas y, en 2013 , un $17,1 \%$ (54.071.370) de 316,1 millones de personas son de origen hispano. Esos datos proporcionados por el American FactFinder demuestran el aumento de 3,6 millones de hispanos en la Unión entre 2010 y 2013. Este aumento se debe a la inmigración y a la alta natalidad por parte de la comunidad latina. Si este crecimiento sigue el mismo ritmo en las próximas décadas, Estados Unidos se convertirá en un país latino.

Como he dicho anteriormente, la inmigración de los hispanohablantes a EE.UU. y su alta natalidad son la causa del aumento de la población en

${ }^{4}$ http ://www.mla.org/cgi - shl/docstudio/docs.pl?map_data_results

${ }^{5}$ http : //www.prensalibre.com/internacionales/Mapa-hispaños - Unidos 


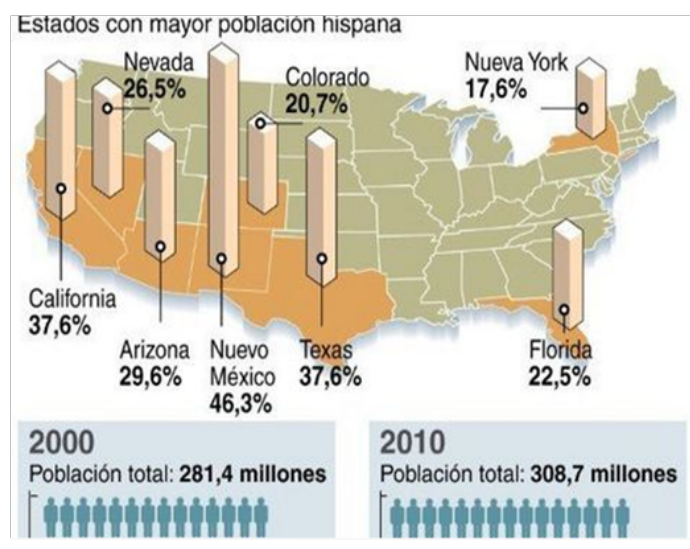

Fig. 3. Población de habla hispana en EE.UU.

el país. Aunque se considera la minoría étnica más amplia de la Unión, la comunidad hispana se caracteriza, con frecuencia, por la alta marginalización y la discriminación, convirtiéndose en desvalidos en la dominante sociedad anglosajona (Mar-Molinero 2009), exceptuando a los latinos provenientes de Cuba que gozan de un estatus social y económico reconocido en Miami y Florida (Moreno Fernández 2013b), razón por la cual el español en esta zona se considera como lengua con prestigio, todo lo contrario al español del Suroeste, que es principalmente el mexicano, considerado una lengua sin prestigio y con connotaciones negativas.

Respecto a la distribución de la población hispana según su origen, la gran mayoría proviene de México (64,3\%), el 22,7\% son de los diferentes países de América Central, el 9,3\% es de Puerto Rico y el 3,7\% es de origen cubano, como muestra la Figura 4 de elaboración propia a partir de los datos del Censo 2012 del centro de estadísticas American Fact Finder

A pesar del sentimiento de inferioridad lingüística -el español se considera una lengua minoritaria en EE.UU.-, se están produciendo cambios en la difusión de la lengua como consecuencia directa de las fuerzas de la globalización. Esto se manifiesta en el hecho de que el español es la marca de identidad de los hispanos y es la lengua de comunicación de las relaciones que los unen.

Teniendo en cuenta lo dicho, resulta más fácil entender el porqué de la existencia de la lengua española en la Unión. Ahora bien, cuando hablamos 


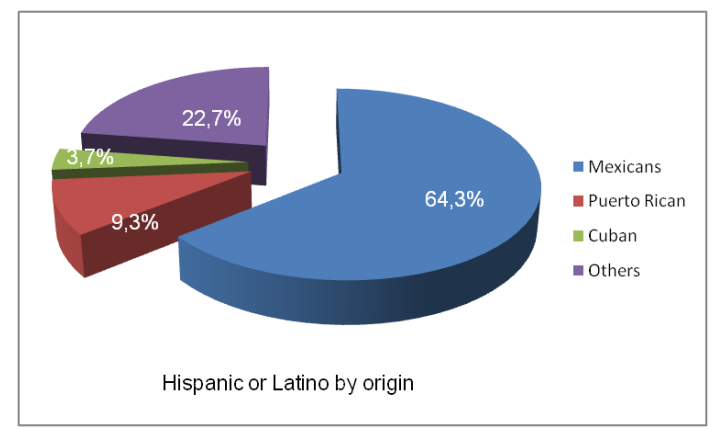

Fig. 4. Distribución de la población hispana en EE.UU. según su origen.

de inmigración en EE.UU. no estamos hablando solo de la inmigración latinoamericana, sino de la inmigración de diferentes partes del mundo, que, como no podía ser de otra manera, ha llevado a EE.UU. sus diferentes lenguas y culturas.

EE.UU. es un país cuya seña de identidad es el inglés. El monolingüismo es la característica que define al americano. Teniendo en cuenta esto, es comprensible que con la llegada masiva de la inmigración se implementaran ciertas medidas que apoyaron las políticas lingüísticas que defienden el monolingüismo inglés. Como ejemplo de esto, basta fijarse en lo ocurrido durante el siglo XX:

- En 1906 uno de los requisitos para obtener la nacionalidad era el dominio de inglés por parte de los inmigrantes; durante y después de la Primera Guerra Mundial aumentó la ansiedad de la lealtad nacional y la asimilación lingüística de los inmigrantes, ya que, en los años posteriores se levantó la prohibición de la enseñanza de idiomas que no fueran el inglés como fruto de la legislación Anti-alemán y el caso conocido como Mayers vs Nebraska.

- En los años 30, la inmigración se detuvo como consecuencia de la estricta legislación adoptada en los años 20 y de la gran depresión económica, lo que llevó a la asimilación lingüística absoluta por parte de los inmigrantes ya residentes en el territorio, potenciando el monolingüismo en la tercera generación de las familias inmigrantes.

- Los años 80 están marcados por el lento crecimiento económico, que aprovechó el movimiento English Only: este movimiento difundió las ideas sobre la necesidad de mantener la lengua inglesa unificada, con el objetivo de declarar el inglés como la lengua oficial, ya que, en realidad, 
en la Constitución de los Estados Unidos de América, firmada en 1787, no se menciona nada respecto a la lengua oficial. Sin embargo, como la Constitución está escrita en inglés, la población norteamericana ha asimilado que su lengua oficial es el inglés. English Only puede considerarse una reacción contra la inmigración y tiene muchos simpatizantes en la actualidad. Su pensamiento ha influido en otros proyectos en contra de la educación bilingüe en las décadas posteriores, como refleja Wright (2012: 615): en California con la Proposition 227 en 1998; en Arizona mediante la Proposition 203 en 2003; y en Massachusetts en 2002 con Question 2. Estas iniciativas defienden que la educación bilingüe viola el derecho de los niños a aprender el inglés y han conseguido reducir el número de los programas bilingües en cada uno de los Estados en cuestión.

Este breve recorrido por los sucesos del siglo XX, que tienen que ver con las lenguas, demuestra la postura política pero también ciudadana que ha favorecido el monolingüismo y que ha traído consigo una serie de consecuencias que han influido negativamente en el mantenimiento de las lenguas de las minorías lingüísticas y han favorecido la asimilación lingüística de los inmigrantes que se han convertido en monolingües en la lengua 'oficial' de los Estados Unidos.

Hay que destacar, por tanto, el monolingüismo como marca de la identidad americana y, a pesar de que estamos en la era global, esta es la base de los puntos de vista nacionalistas propios de la cultura occidental y eso se manifiesta en el empleo de la lengua en la administración pública, en el ámbito jurídico, en los medios de comunicación y, particularmente, en el sistema educativo que es el fruto de las ideas y creencias respecto al repertorio de la lengua de la comunidad (Mar-Molinero 2009).

\section{Español en EE.UU.: Análisis Sociolingüístico}

Para analizar la situación del español en los Estados Unidos, es necesario analizar 'comunidades de habla' concretas, ya que esta aproximación permite observar la presencia del español en ámbito formal a nivel nacional. En concreto, en este trabajo analizamos la administración pública y jurídica, los medios de comunicación y, por supuesto, el ámbito más relevante en las lenguas minoritarias, la educación. 


\subsection{Administración Pública y Ámbito Jurídico}

El español está presente en la vida pública de los norteamericanos. El gobierno de los Estados Unidos ofrece en español toda la información que incumbe a cualquier ciudadano norteamericano. Un buen ejemplo son las páginas de Internet de los principales órganos del gobierno que ofrecen la opción de consulta en español. En concreto, desde 2009, la Casa Blanca ofrece la nueva página en español ${ }^{6}$, lo que supone un paso más hacia la comunicación en español al presentar contenidos específicamente dirigidos a la comunidad hispana. En español también se ofrece la agenda del presidente Obama relacionada con la comunidad latina del territorio. Incluso en las redes sociales - www.twitter.com o www.facebook.com-, éste mismo órgano ofrece a sus seguidores hispanohablantes acceder a las noticias relacionadas con los sucesos en el país. El hecho de que el español esté presente en el corazón de los Estados Unidos -la Casa Blanca- muestra que los hispanohablantes en EE.UU. y su lengua tienen cada día más facilidades desde el punto de vista lingüístico.

Por otra parte, no hay que olvidar los servicios públicos que atienden diariamente a los ciudadanos (desde los hospitales hasta los servicios jurídicos). Según las estadísticas del Departamento de trabajo de EE.UU. ${ }^{7}$, en 2012 había 63.600 intérpretes y traductores de inglés y otra lengua extranjera y, según los pronósticos para el 2022, este ámbito laboral, supondrá un aumento de un $46 \%$, como consecuencia del gran número de personas que no hablan inglés en la Unión, con el objetivo de facilitarles la comunicación en escuelas, hospitales, tribunales y centros de conferencias. En lo referente a la lengua española, el poder que están adquiriendo los hispanohablantes en el territorio ha fomentado la creación de todo tipo de servicios en las zonas que comprenden una alta concentración de latinos, principalmente en las ciudades cercanas a la frontera con México, lo que hace posible vivir en estas zonas "sin necesidad de saber mucho inglés" (Lynch 2008: 249).

\subsection{Medios de Comunicación}

Según datos del Instituto Cervantes (Centro Virtual Cervantes 2012), el poder de compra de los hispanos es el más alto entre los grupos minoritarios desde

${ }^{6}$ http://www.whitehouse.gov/espanol/

${ }^{7}$ http ://www.bls.gov/ooh/media - and - communication/interpreters - and translators.htm 
2008, y esto se refleja en todos los ámbitos, entre ellos, los medios de comunicación. Hay varios estudios que analizan y describen las cadenas televisivas que emiten su contenido en español y su crecimiento en las últimas décadas estrechamente relacionado con el ascenso de los latinos. En la actualidad, a pesar de que una gran parte de la población consume noticias a través de los medios online y de las redes sociales, las estadísticas demuestran que el medio de comunicación que más seguidores tiene entre la población es la televisión. Según los datos de TVB, la asociación comercial de la industria de televisión y emisoras, la televisión es el medio de comunicación con mayor porcentaje de consumidores a nivel nacional con un $88,3 \%$ de audiencia.

Respecto a la comunidad hispana y su crecimiento a nivel demográfico y económico, no es de sorprender que el número de las cadenas que emiten en español se haya incrementado progresivamente, con un significativo número de canales que están disponibles actualmente en EE.UU. Entre las más destacadas, hay que mencionar las siguientes: Univision, creada en 1967; Telemundo, desarrollada en 1954 en Puerto Rico y desde 1987 con la cobertura en Norteamérica; Telefutura, cadena asociada a Univisión, y Azteca America, en funcionamiento desde 2001. Estos cuatro canales son los que más audiencia captan entre los hispanos americanos, no obstante la cadena más prestigiosa y con mayor porcentaje de audiencia, según el centro de estadísticas Nielsen (www.nielsen.com), es sin duda Univision. Actualmente representa un grupo mediático que engloba televisión, radio e Internet. Ya en 2011, fue la TV de habla hispana que compitió con las grandes cadenas nacionales, entre ellas, Fox, $C B S, A B C$ y $N B C$, como muestra la Figura $5^{8}$.

En este repaso a los medios de comunicación, no hay que olvidar la televisión por cable, disponible en muchos hogares de hispanohablantes. En este caso, destacan CNN en Español, InfoMás, Fox Hispanic Media, etc.

Obviamente, el español está presente también en las emisoras de radio y en la prensa escrita, aunque este último medio ha sufrido cierto declive como consecuencia de las nuevas tecnologías. En concreto, hay que destacar las revistas La Opinión (Los Ángeles), El Nuevo Herald (Miami) y El Diario/La Prensa (Nueva York) que se consideran las más importantes en lengua española. La Figura $6^{9}$ refleja el auge de estos medios de comunicación escrita.

\footnotetext{
${ }^{8}$ Extraída de http : //stateofthemedia.org/2011/hispanic - media - fairing better - than - the - mainstream - media/

${ }^{9}$ Extraída de http : //stateofthemedia.org/2011/hispanic - media - fairing better - than - the - mainstream - media/
} 


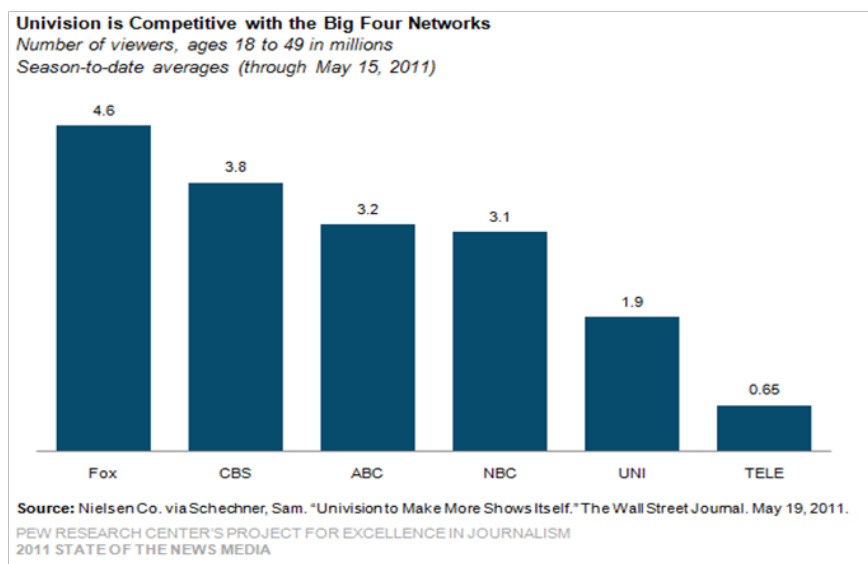

Fig. 5. Cadenas de televisión.

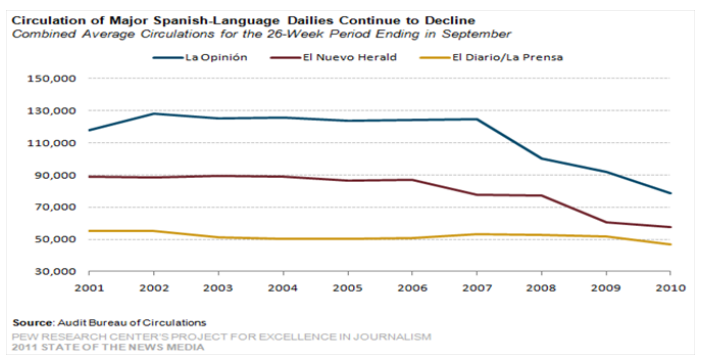

Fig. 6. Prensa escrita en español.

Respecto a las revistas online, en Estados Unidos, hay una gran variedad de 'online newspapes' en lengua española. En total contamos con cerca de 117 revistas, de las que la gran mayoría están escritas exclusivamente en español y algunas son bilingües, como por ejemplo Washington's Voz o Bilingual News ${ }^{10}$.

\subsection{Educación}

La educación en segundas lenguas en los Estados Unidos es un tema muy delicado, ya que está vinculado a la inmigración y a los acontecimientos de $\overline{10}$ http : //www.onlinenewspapers.com/usstate/spanish - language newspapers - usa.htm 
los años 60 relacionados con la lucha por los derechos civiles y la igualdad de oportunidades.

En 1968, se dio un gran paso respecto a la educación bilingüe con The Bilingual Education Act (BEA) que se firmó en 1968 y que representa el primer reconocimiento oficial de las necesidades de los estudiantes con capacidad limitada en inglés. Estamos ante la primera autorización de la educación bilingüe en EE.UU. con posteriores reautorizaciones de la Ley en 1974, 1978, 1984, y 1988 (Stewner-Manzanares 1988). Este programa se consideró un reconocimiento para las minorías. El principal cambio del BEA afectó a la educación primaria y secundaria que a partir de este momento contaba con instrucción en otra lengua que no fuera el inglés, proporcionando así igualdad educativa a los niños cuya primera lengua no era la lengua mayoritaria. El objetivo real de esta ley fue promover el aprendizaje rápido y eficaz de los hijos de inmigrantes que hablaban inglés, que aprendiendo esta lengua podrían participar más en las actividades escolares y obtener mejor rendimiento académico (Montrul 2013). Las reautorizaciones de esta Ley reflejan la tensión social y política que suponía la educación bilingüe, razón por la cual se empezó a dar mayor énfasis a los programas transicionales que aseguraban el éxito de los estudiantes en el dominio de la lengua inglesa y, de esta manera, su posterior traslado a las lenguas cuya instrucción era solo en la lengua dominante (Wright 2012).

Con esta ley, muchos temían, y todavía hoy en día temen, que la educación bilingüe se convierta en un problema para el nacionalismo y su desarrollo, ya que si los niños reciben la educación en sus lenguas étnicas, "estas pueden ganar importancia y convertirse en símbolos de un nacionalismo opuesto a la nación" (Fasold 1996: 26). Algunos han mantenido que la educación bilingüe es "a violation of students rights to learn English" (Wright 2012: 615). Estas perspectivas tienen mucho que ver con los movimientos que surgieron en los años 90 (California, Arizona y Massachusetts) como reacción ante el gran porcentaje de estudiantes de familias inmigrantes. El principal argumento de estos movimientos ha sido que el aprendizaje no tenía ninguna eficacia en los programas bilingües.

El BEA expiró en 2001 con la aprobación, bajo el mandato de George Bush, del No Child Left Behind (NCLB). Esta Ley afecta a la educación primaria y secundaria. Su principal el objetivo es mejorar la educación a nivel nacional, es decir, el rendimiento y los resultados de los alumnos. Los responsables de cumplir estos objetivos son los distritos escolares que están obligados a 
presentar anualmente un informe sobre la eficacia de la enseñanza y sobre el progreso de los estudiantes en las materias evaluadas que comprenden las matemáticas y la lengua.

La iniciativa ciudadana, dirigida por sus representantes, ya representaba un paso atrás para la educación bilingüe y la integración de los inmigrantes en EE.UU. con la aprobación de la Proposición 227 de California en 1998 y con medidas similares en Arizona y Massachussets, pero la ley NCLB puede considerarse un claro retroceso en la educación de los inmigrantes y sus hijos, como refleja el TITLE III que trata el Language instruction for limited English proficiente and inmigrant students y cuyos objetivos vienen reflejados en la PART A, Sec. 3102:

- Alcanzar alto grado de inglés, cursar los mismos contenidos académicos y obtener los mismos estándares de logros que los demás niños.

- Desarrollo de programas de enseñanza del idioma de alta calidad para acceder a la instrucción de todos los ingleses.

- Implementar y sostener programas de enseñanza de idiomas y programas de desarrollo del inglés.

- Promover la participación de los padres y de la comunidad en los programas de enseñanza del idioma.

- Flexibilidad para implementar los programas de enseñanza del idioma que las agencias crean que son los más eficaces para la enseñanza del inglés.

- Sostener las agencias educativas estatales por los aumentos de dominio del inglés y del conocimiento del contenido académico en inglés, exigiendo:

- las mejoras en el dominio del inglés demostradas cada año fiscal;

- el progreso anual de los niños LEP, que comprende las matemáticas y la lengua.

Estos son los objetivos principales disponibles en la página de internet del U.S Departament of Education.

Como puede observarse, esta ley promueve claramente la enseñanza de la lengua dominante y de prestigio, el inglés. El contenido de la Parte III que trata sobre los estudiantes inmigrantes y los LEP (Limited English Proficient Student) no contienen ninguna referencia respecto al aprendizaje bilingüe, con la finalidad de poseer la capacidad comunicativa en una segunda lengua.

En los Estados Unidos hay familias de origen hispano que son monolingües en su lengua de origen, el español, lo que genera un gran fracaso escolar de 
los hispanos (Pomerantz \& Huguet 2007), razón por la cual existen programas bilingües dedicados a la alfabetización de las minorías con el español como lengua dominante y, así, ofrecer las mismas oportunidades de acceso a la educación de toda la población norteamericana. No obstante, este tipo de programas están especialmente dedicados a los niños de los inmigrantes con el objetivo de que entren en contacto con la lengua inglesa y de que consigan progresivamente un nivel avanzado en esa lengua. Por ello, en Estados Unidos, encontramos programas duales que permiten a los estudiantes la inmersión en la lengua inglesa tanto en la enseñanza primaria como en la secundaria. En concreto, los programas bilingües constan de tres fases, como refleja Pomerantz y Huguet (2007: 519-524):

1. Transicional: Este modelo, a pesar de que es considerado como un programa bilingüe, fue diseñado para la rápida asimilación de la lengua inglesa y, por tanto, la lengua materna sirve de puente en la transición hacia el inglés. Puede decirse que estamos ante un modelo asimilacionista, ya que el resultado final de estos programas son bilingües sustractivos, aunque con el soporte que les permite permanecer en la escuela. En otras palabras, el objetivo del programa transicional es la alfabetización en inglés, y el español es la herramienta que facilita el acceso al contenido del programa escolar mientras los alumnos aprenden el inglés. Respecto a este programa, hay que destacar que es el más común de los programas bilingües en los Estados Unidos y posee distintos grados (Myers-Scotton 2006): Early exit programs, Late exit programs y Structured inmersion programs. En los tres programas, el niño recibe la instrucción en su lengua materna para posteriormente entrar en la clase de enseñanza solo en inglés, es decir, con los estudiantes nativos.

2. Mantenimiento: Estos programas comprenden las clases de transición con contenido en inglés y con apoyo en su primer idioma. La gran diferencia entre el programa transicional y el de mantenimiento es que los alumnos reciben las clases de lengua y literatura en su lengua materna, lo que les permite leer y escribir en español. El objetivo de los programas bilingües de mantenimiento es promover el bilingüismo; en lugar de un objetivo asimilacionista, este modelo promueve el pluralismo. Es decir, el idioma es visto como un recurso.

3. Enriquecimiento: En realidad, estamos ante un programa bilingüe real, ya que las clases comprenden la participación tanto de los alumnos nativos anglosajones como de los no nativos, con el mismo porcentaje por clase, 
y los dos grupos reciben tanto la instrucción en la L1 como en la L2. Los prototipos más comunes son 50:50 y 90:10; es decir, en el primer caso, los niños reciben el $50 \%$ de la instrucción en inglés y otro $50 \%$ en una segunda lengua; en el segundo caso, la L1 comprende el 90\% del contenido de la instrucción y la L2 un 10\%. Hay escuelas que prefieren los modelos 80:20 o 70:30, que operan de la misma manera pero incluyen mayor presencia de la lengua mayoritaria, el inglés. En realidad, estamos ante el programa bilingüe más efectivo de todos los programas que engloba la educación bilingüe, según los estudios comparativos realizados en los Estados Unidos (Wright 2012: 610) en concreto, el 90:10 se considera como el más efectivo ya que desarrolla el nivel avanzado de la capacidad comunicativa, ya desde la temprana edad en las dos lenguas (Rhodes \& Pufahl 2014).

Otros programas son los siguientes:

1. Español como lengua adicional (Second Language Adquisition, SLA). Es el programa dirigido a los monolingües anglosajones con comienzo a los 13-14 años, pero también está disponible en las escuelas primarias y universidades.

Las escuelas primarias ofrecen programas centrados en la enseñanza del lenguaje, exploratorios y de inmersión. El aprendizaje del español es opcional y se entiende como una actividad extraescolar de 20-30 minutos semanales y como enseñanza diaria con el objetivo de la bialfabetización y la biculturación, aunque la mayoría de las escuelas ofrece 4-5 sesiones semanales de 45-60 minutos (Pomerantz \& Huguet 2007), incluso menos. Por tanto, es muy difícil determinar la capacidad comunicativa de los alumnos, y más del $40 \%$-el $44 \%$ en 2008 - de los programas de primaria tienen como objetivo poner en contacto, de manera introductoria, al alumnado con la lengua española mediante cursos de tipo exploratorio (Rhodes \& Pufahl 2014).

En educación secundaria también encontramos los programas de enseñanza del español, pero ya centrados en el aprendizaje de la lengua y la capacidad comunicativa, ya que solo el $5 \%$ son de tipo exploratorio. Respecto a la evaluación, los alumnos pueden someterse de manera voluntaria a un examen opcional, por lo tanto, no se evalúa el nivel alcanzado por el estudiante ni tampoco la calidad del programa (Pometantz \& Huguet 2007), en muchas ocasiones es suficiente la asistencia. Por tanto, no es de sorprender que la mayoría de los estudiantes curse este tipo de 
programa ya que el alumno que quiere obtener el acceso a la universidad debe asistir a clases de una L2 al menos durante 2 años.

2. Español como lengua heredada. Este programa está orientado a los estudiantes bilingües, principalmente de origen hispano que desean continuar con el estudio de la lengua española o simplemente mantener la lengua de sus antepasados y a los estudiantes con perfecto dominio de inglés, pero con distintos grados de dominio de español. Por lo tanto, las clases están compuestas por estudiantes con habilidad avanzada en español pero también por estudiantes con un dominio limitado. Sin embargo, muchos estudios recalcan las experiencias negativas de estos estudiantes (Lynch 2013; Pomerantz \& Huguet 2007) por el simple hecho de que el modelo seguido es el del español peninsular. La mayoría de los estudiantes aprende el español en casa, también llamado Kitchenspanish, por lo tanto, utilizan la variedad no-estándar de la lengua, y a eso hay que añadir el cambio de código (code-switching). Por otra parte, muchos alumnos de origen hispano deciden no asistir a este tipo de programa por su denominación; es decir, no lo perciben como un programa para bilingües, sino como un programa para nativos y debido a su nivel y variedad de español prefieren cursar SLA.

Los programas enumerados son los que están presentes en la vida de los hispanos y de todos los inmigrantes en la Unión. A través de ellos puede verse la actitud y las políticas lingüísticas del país; es decir, la política educativa general de los EE.UU es promover el inglés, considerada la lengua de éxito académico y movilidad social. Los programas bilingües más comunes son los de transición rápida al inglés con el objetivo de la asimilación rápida a la educación general, contribuyendo a la pérdida progresiva de la lengua materna en los niños inmigrantes. A todo esto hay que añadir que, de 1976 a 2011, el porcentaje de los estudiantes hispanos ha pasado del $4 \%$ al $14 \%^{11}$.

Como defienden la mayoría de los autores (Montrul 2013; Pomerantz \& Huguet 2007; Baker 2006), la política educativa general de los Estados Unidos apoya el monolingüismo y no muestra ninguna interés en mantener las lenguas de los grupos minoritarios, ya que casi las descarta de los planes de estudio. Sin embargo, el mantenimiento de una lengua, en gran parte, depende del apoyo en el ámbito familiar. Es decir, la transmisión intergeneracional es la clave para evitar la sustitución lingüística que queda reflejada en el uso y el mantenimiento de la lengua.

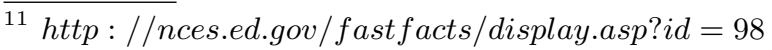




\subsection{Estadísticas}

Hasta el momento he mencionado los ámbitos en los que la lengua española ha penetrado en las últimas décadas en EE.UU. Sin embargo, para esclarecer la situación del español en los Estados Unidos hay que tener en cuenta los datos y estadísticas realizadas por individuos concretos, es decir, por los hispanos que viven allí, ya que ignorar al hablante como individuo es negar la realidad lingüística, que queda reflejada en las actitudes y manifestaciones lingüísticas de los propios latinos.

\section{Transmisión Intergeneracional}

Es bien sabido que, la transmisión intergeneracional del español siempre ha sido siempre débil, a pesar de que el censo de 2000 refleja que el español es la lengua más hablada en los hogares estadounidenses, tanto en los hispanos como en los no hispanos. Sin embargo, fijándose en los censos de los últimos años, parece que el uso del español se va reduciendo paulatinamente (Moreno Fernández 2013a), es decir, los hispanos siguen el patrón aceptado por los americanos. A pesar de la continua inmigración, la lengua tiende a desaparecer en las familias de inmigrantes y deja de transmitirse en la tercera o cuarta generación. En concreto, este patrón tiene las siguientes características:

- Los inmigrantes recién llegados al país tienen como lengua dominante el español, de la misma manera que la primera generación ya nacida en EE.UU. aunque muestran un dominio alto de inglés y, a partir de esta generación, comienza la asimilación lingüística.

- A partir de la segunda generación los latinos no tienen el español como lengua dominante. En algunos casos, hay padres que hablan español pero poco y con poca frecuencia. Transmitirán a sus descendientes un modelo de la lengua incompleto, por lo que serán bilingües con un conocimiento básico de vocabulario y algunas expresiones (Montrul 2013).

- A partir de la tercera generación, la cultura estadounidense está ya bastante asimilada, razón por la cual los de tercera generación suelen ser monolingües en inglés, aunque no todos, ya que algunos dominan algunas expresiones, pero casi no hablan español.

- Las cuartas generaciones ya no transmiten la lengua a sus hijos, por tanto, la lengua ya ha desaparecido de la familia. 
Este patrón intergeneracional es la lógica consecuencia de la presión social y cultural que obliga a aprender el inglés, por lo que los inmigrantes a su llegada al país se dan cuenta de que para mejorar su situación laboral han de aprender el idioma dominante, ya que, en caso contrario, solo pueden optar a empleos relacionados con la jardinería, la agricultura o la limpieza. Por tanto, la gran necesidad de dominar el inglés crea una presión que se ve reflejada en la actitud de los padres hacia la educación de sus hijos. Andrew Lynch (2008) destaca los estudios que han demostrado que en la mayoría de las familias latinas en EE.UU., muchos padres son los que exigen la educación de sus hijos solo en inglés. Por ejemplo, el autor menciona los estudios de Schecter y Bayley (2002) y de Farr y Domínguez Barajas (2005b). Estos autores exponen las reacciones de padres cuando se enteraron que sus hijos iban a asistir a un programa bilingüe:

Uno de los padres del estudio de Schecter y Bayley (2002) insistió en que toda la educación primaria de su hijo fuera en inglés, a pesar de que en casa se recalcara la importancia del español y se hablara con el hijo siempre en esa lengua. Cuando se enteró de que su hijo iba a estudiar en un programa bilingüe, Raúl se negó:

Les dije yo que no, que si le iban a poner en el salón bilingüe yo lo sacaba de la escuela y lo ponía en otra escuela, porque el español estoy yo pa' enseñárselos [sic]... Yo los mando a la escuela a enseñarles en inglés, no el español. Si yo quisiera que supieran el español me los llevo a México, verdad.

Farr y Domínguez Barajas (2005b) encontraron lo mismo entre familias mexicanas radicadas en Chicago. Una madre, inmigrante de México, explicó que cuando una de sus hijas fue asignada a un programa bilingüe tuvo miedo de que se confundiera y exigió que no le enseñaran en español:

... cuando yo me di cuenta, hablé con la maestra y le dije que se iba a confundir mucho teniendo los dos [idiomas], que por qué no me hacía favor de ponerla nomás en inglés...Porque entonces el español lo iba a aprender aquí en casa, ¿verdad? ... Muchos niños pierden el tiempo porque los tienen confundidos (Farr \& Domínguez Barajas 2005b: 55).

Un padre del mismo estudio en Chicago expresó que para él sus hijos tienen la obligación de usar solo inglés en la escuela: 
... [la educación bilingüe] es un tratamiento especial porque si nosotros aprendimos inglés, lo aprendimos por obligación, por necesidad del trabajo. Los hijos que son nacidos aquí tienen que aprender el inglés con más razón porque ellos son de aquí. Este es su país de ellos, así es que obligatoriamente tienen que saber ellos un inglés perfecto. Eso es obligatorio (Lynch 2008: 250)

Estos estudios empíricos señalan claramente que el patrón intergeneracional está vigente hoy en día y apoyan la hipótesis de que la vitalidad de la lengua española en EE.UU. se mantiene gracias a los inmigrantes recientes, ya que una vez establecidos en el país comienza el proceso de asimilación norteamericana.

Por otra parte, las primeras generaciones ya nacidas en la Unión, cuando entran en la adolescencia son los 'rompedores lingüísticos', como los considera Myers-Scotton (2006: 101-106), ya que son los niños los que deciden la lengua que se usa en casa de las familias inmigrantes. Según este autor, hay estudios que demuestran que, por norma general, eligen la lengua dominante, el inglés, porque es la lengua de comunicación más amplia que los acompaña en todas sus actividades. Aunque los padres tienen una actitud positiva hacia su primera lengua, en la comunicación con los hijos utilizan la L2, por lo que el code switching es muy común. Si esta postura hacia la transmisión de la lengua se mantiene, es lógico pensar que la lengua española irá desapareciendo en las generaciones posteriores.

El primer factor que marca en cierta manera la vitalidad de español en EE.UU. es la inmigración, por tanto, hay que tener en cuenta el origen de la población hispana.

Según los datos aportados por la organización PewResearch el 29 de abril 2014, de los 52,9 millones de hispanos, 34,1 (73,6\%) han nacido en EE.UU. y 18,8 millones $(26,4 \%)$ han nacido fuera del país. Este dato es significativo, ya que ilustra que el 73,6\% de latinos pertenecen a varias generaciones y, teniendo en cuenta el patrón generacional, es muy probable que la gran mayoría de ellos no domine la lengua española.

Otro factor importante es la identidad, cuya seña principal es la lengua. The Huufington Post's Latino Voices publicó una encuesta preguntando a sus lectores si el español era un requisito cultural para los latinos. Lo más sorprendente fue el resultado, ya que mientras el $36 \%$ considera que la lengua es crucial, el $64 \%$ piensa que hablar español no es un requisito cultural para 
los latinos. Por otra parte, el PewResearch también realizó un informe sobre los hispanos y la identidad, y una de las preguntas trataba sobre cómo se describen los hispanos a sí mismos, y el resultado es el que muestra la Figura $7^{12}$

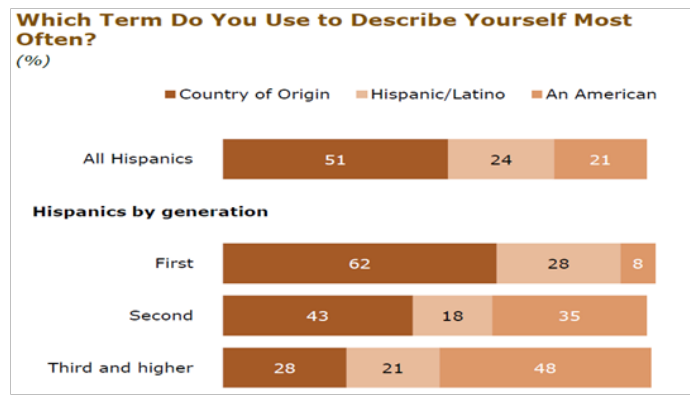

Fig. 7. Hispanos e identidad.

Como puede observarse, hay una gran diferencia en las respuestas, según varía la generación del entrevistado. Es lógico que los que pertenecen a la primera generación se definan según el país de procedencia. A partir de la segunda generación, el porcentaje de los entrevistados que se consideran americanos va aumentando. Según estos datos, a partir de la tercera/cuarta generación, los nacidos en EE.UU. se consideran estadounidenses y suelen ser estas generaciones las que ya están absolutamente asimiladas a la cultura y a la lengua estadounidense.

\section{Los Hispanos y el Uso de la Lengua}

Respecto a la lengua, Emili Prados y Matilde Delgado (2007) en un artículo sobre la televisión hispana en los Estados Unidos, elaboraron varias estadísticas, una de las cuales sobre la lengua en la que se encuentran más cómodos los hispanos en EE.UU. Este trabajo muestra cómo el patrón generacional se hace más que evidente, ya que las primeras generaciones nacidas en el país prefieren y se sienten más cómodas utilizando el inglés. No es de sorprender, por tanto,

${ }^{12}$ Extraída de http : //www.pewhispanic.org/files/2012/04/PHC - Hispanic Identity.pdf 
el resultado de las encuestas mencionadas anteriormente, relacionadas con la identidad.

El patrón generacional, como resultado de la transmisión intergeneracional, se refleja en las estadísticas que comentamos a continuación, extraídas del informe de PewResearch de 2009, actualizado en 2013.

Estimulación del uso español en el ámbito familiar. No es sorprendente que los padres nacidos fuera de la Unión sean más propensos a fomentar el uso del español en casa. Según los datos, el $84 \%$ de los hispanos que pertenecen a la primera generación afirman que sus padres les animan a hablar español, frente al $21 \%$ que apuesta por el inglés. En las segundas generaciones, el $60 \%$ de los padres intentan fomentar el uso del español frente al $18 \%$ que se decanta por el uso del inglés en casa. En lo referente a la tercera generación, el porcentaje de los que desafían a sus hijos para que hablen español es de un 33\%, mientras que un $31 \%$ prefiere el inglés.

Dominio del español. A partir de la segunda generación, el dominio del inglés asciende a un $98 \%$, en comparación con el $48 \%$ en la primera generación (PewResearch Center 2009: 31). El dominio del español va disminuyendo a partir de la segunda generación, reduciéndose el porcentaje considerablemente en la tercera. Como muestra la Figura 8, el $89 \%$ de los hispanos de primera generación muestran capacidad de expresión oral y el $90 \%$ de expresión escrita, contrastando claramente con la tercera generación en la que solo un $38 \%$ de los hispanos presentan dominio oral y un $26 \%$ dominio escrito. Esta gran diferencia está relacionada con la transmisión intergeneracional y con el dominio del inglés, cuestiones que hemos tratado anteriormente.

Preferencia de lengua en medios de comunicación. En la primera generación, un $48 \%$ prefiere las noticias en español, un $26 \%$ tanto en español como en inglés y un $26 \%$ solo en inglés. En la tercera generación estos números cambian netamente, ya que un $91 \%$ prefiere escuchar las noticias en inglés, un $7 \%$ tanto en inglés como en español, y solo el $2 \%$ elige las noticias con el contenido en español.

Esta misma tendencia se encuentra si analizamos los medios de comunicación de tipo auditivo, ya que un $56 \%$ de los latinos de primera generación escucha música en español, un $26 \%$ indiferentemente en español e inglés, y un $17 \%$ solo en inglés. En contraste con la tercera generación, en la que un $3 \%$ escucha música solo en inglés, un $27 \%$ tanto en inglés como en español y un $69 \%$ solo en inglés. 


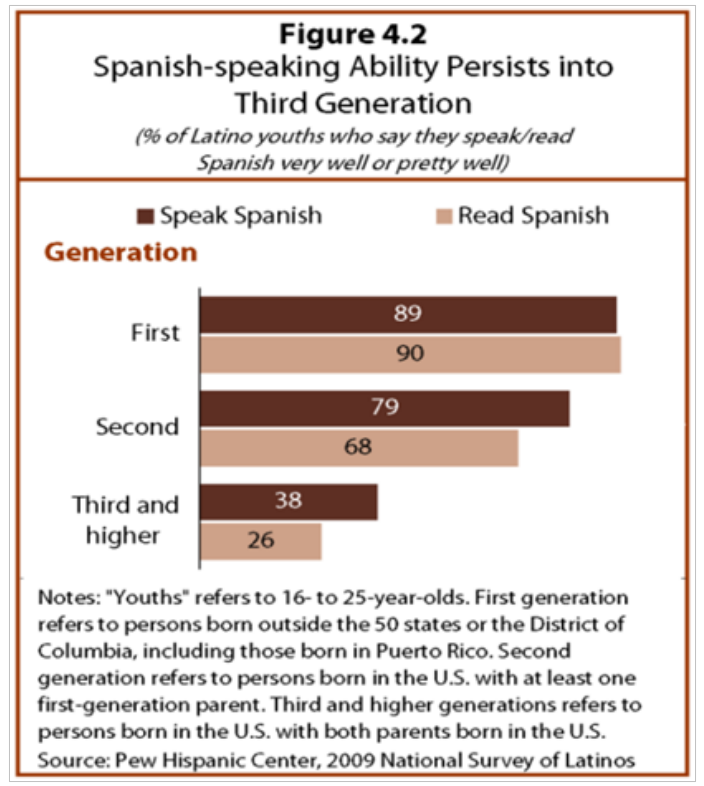

Fig. 8. Dominio de español de hispanohablantes según las generaciones.

Uso del Spanglish. Un $47 \%$ de la población latina en EE.UU. utiliza en ocasiones esta lengua criolla y un $23 \%$ la usa muy a menudo. Pero es la segunda generación la que muestra una mayor tendencia a emplear muy a menudo esta lengua híbrida, un $53 \%$ la utiliza de vez en cuando, como puede observarse en la Figura 11.

A partir de lo que hemos dicho, podemos observar cómo la cuestión lingüística puede verse reflejada en la elección de la lengua en cualquier actividad cotidiana. Teniendo en cuenta que estamos ante un continuo contacto de lenguas, no es de sorprender que, en muchas ocasiones, una gran parte de los hispanos se vea influido por el fenómeno conocido como spanglish, que comprende la mezcla de los dos idiomas tanto a nivel gramatical como a nivel semántico, con cambio de código en una misma oración. En muchos casos, se trata principalmente de la creación de palabras cuya raíz pertenece al inglés con afijos del español, por ejemplo, verbos como mixtear, pushar, etc. o sustantivos como troca o yarda. Es evidente que este vocabulario no está aceptado por la RAE, pero el spanglish es una 'lengua' usada por un gran número de hispanos en EE.UU. Estas tendencias de uso pueden llevar a una nueva variedad de es- 


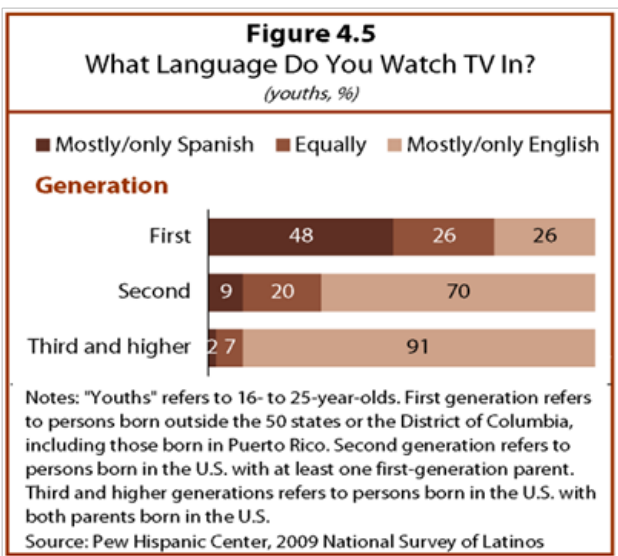

Fig. 9. Preferencia de lengua en los medios de comunicación.

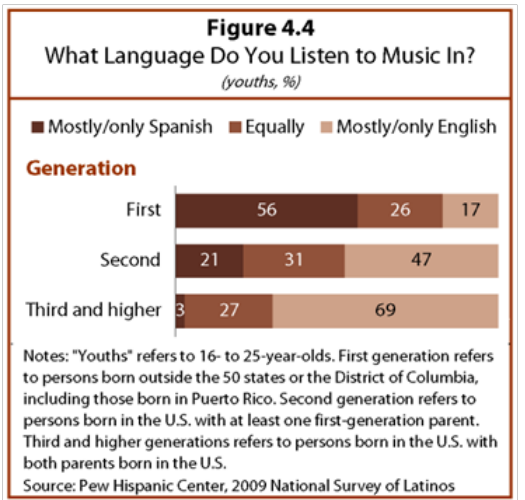

Fig. 10. Preferencia de lengua en los medios de comunicación.

pañol, que hoy en día no está aceptada, que tiene muchos seguidores y que despierta actitudes tanto positivas como negativas.

A los datos expuestos hasta ahora, hay que añadir las previsiones realizadas por diversos centros de estadísticas, como el Bureau y PewResearch Center. Según el Gobierno de EE.UU., en 2050 la población de origen hispano estará compuesta por 128,8 millones de individuos, lo que significa un $30,74 \%$ de la población, en contraste con el $17,2 \%$ en la actualidad. Por otra parte, el PewResearch Center considera que el aumento de la población de origen 


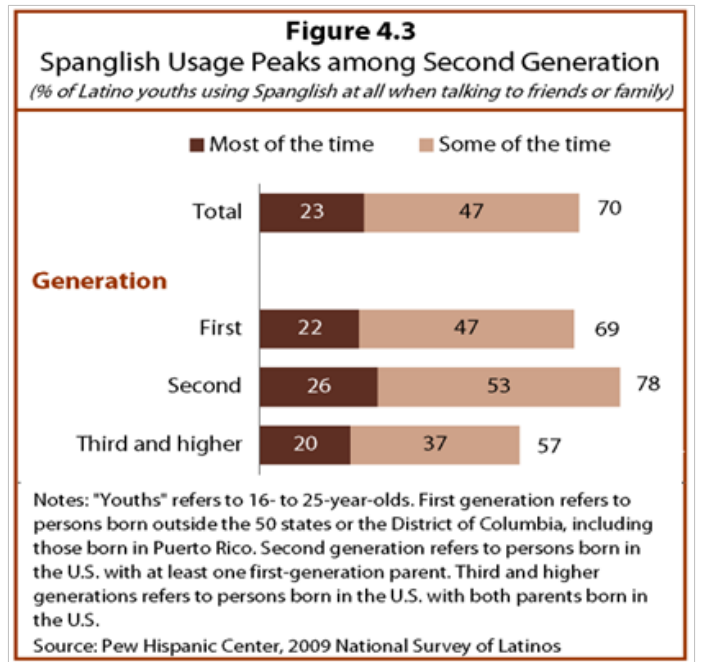

Fig. 11. Uso de spanglish entre diferentes generaciones de hispanos.

hispano será la consecuencia del incremento de las segundas, terceras y posteriores generaciones, y las primeras generaciones descenderán de un 33,8\% a un $26,9 \%$ (Figura 12).

Por tanto, puede afirmarse que la lengua española depende del porcentaje que constituye cada grupo de generación dentro de la comunidad hispana, pero también del nivel de la inmigración que es muy importante para la vitalidad de la lengua y que, desde el año 2000, ha ido disminuyendo paulatinamente como consecuencia de las políticas de migración adoptadas por el gobierno federal. Por otra parte, también hay que fijarse en el nivel de educación que llegan a cursar la mayoría de los hispanos en EE.UU. Es cierta la consideración de Humberto López Morales que afirma en el Anuario Cervantes 2008 lo siguiente:

Pero al margen de la demografía, los datos arrojados por las estadísticas oficiales del último decenio comprueban que paso a paso van aumentando los índices de escolarización de los hispanos y, consecuentemente, su situación laboral. Los hispanos serán más educados y cultos y obtendrán más ingresos por sus trabajos. Poco a poco dejarán de ser un grupo numeroso pero, en general, tenido -no sin ciertas razones- por ineducado y pobre, para convertirse en uno más 


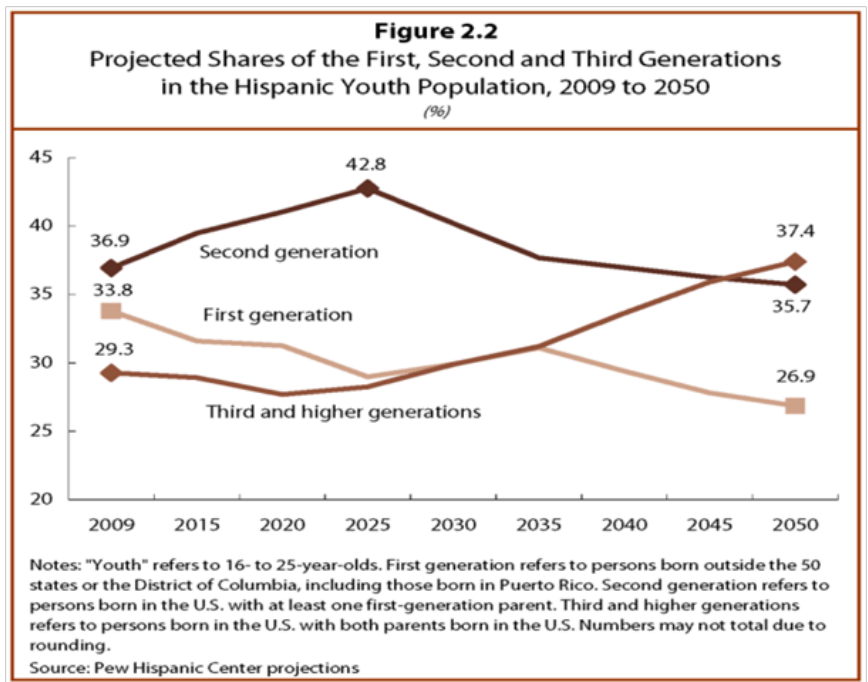

Fig. 12. Proyección de la población hispana en EE.UU. hasta 2050, según generación.

numeroso aun, pero de naturaleza sociocultural muy diferente (López

Morales 2008: 1036).

No obstante, hay que tener en cuenta el sistema general de educación de EE.UU. y las esperanzas de los jóvenes hispanos, ya que estas tienen que ver con el dominio de las lenguas. En concreto, un $24 \%$ de los que principalmente hablan español aspiran a obtener algún título, en comparación con el $49 \%$ de los bilingües y el $62 \%$ de los que dominan el inglés que dicen lo mismo (PewResearch 2009: 51). Es decir, el dominio del inglés es imprescindible para poder acceder a los estudios superiores, razón por la cual la asimilación lingüística es casi inevitable.

Respecto a los estudios superiores, es verdad que en las universidades ha aumentado el número de los departamentos de lenguas románicas, no obstante, el número de interesados en los estudios superiores de lengua y literatura hispánicas es muy inferior en comparación con otras carreras. Según el National Center for Educational Statistics, hay 4726 universidades en Estados Unidos entre públicas y privadas, en las que en el curso 2011-2012 habían cursado 1,8 millones de estudiantes una carrera, 754 mil un máster y 170 mil se estaba 
doctorando. Las carreras más solicitadas son biología, marketing y negocios, comunicación y educación. Respecto a los estudios de lenguas extranjeras a nivel universitario, de los 21,8 mil alumnos universitarios, solo 8,7 mil estaban matriculados en estudios de lengua y literatura hispánicas, 991 realizaban un máster en este ámbito y 189 estaban doctorándose. Como puede observarse, el número de alumnos que muestran interés en el estudio del español es muy bajo, hecho que puede deberse a que los departamentos de románicas son frecuentes solo en las grandes universidades de renombre (García 2013), no accesibles para cualquiera.

\section{Español en Texas}

A modo de ejemplo, para esclarecer la situación del español en EE.UU., nos centramos en este apartado en uno de los Estados de EE.UU. en los que es más esperable una situación de bilingüismo: Texas. Texas es uno de los estados con mayor concentración de población hispana en la Unión, por tanto, cabría esperar una situación de bilingüismo español-inglés.

Texas es uno de los estados que formaba parte de México y que, por razones sociopolíticas, fue anexionado al territorio anglosajón en 1848, después de la guerra de México americana. Actualmente, el estado de Texas por su demografía es el más grande de EE.UU., exceptuando Alaska, y cuenta con una población de 26,2 millones de personas, que constituyen el 8,3\% de la población total de la Unión. De los 26,2 millones de habitantes de Texas, un $38,8 \%$ es de origen hispano (Figura 13).

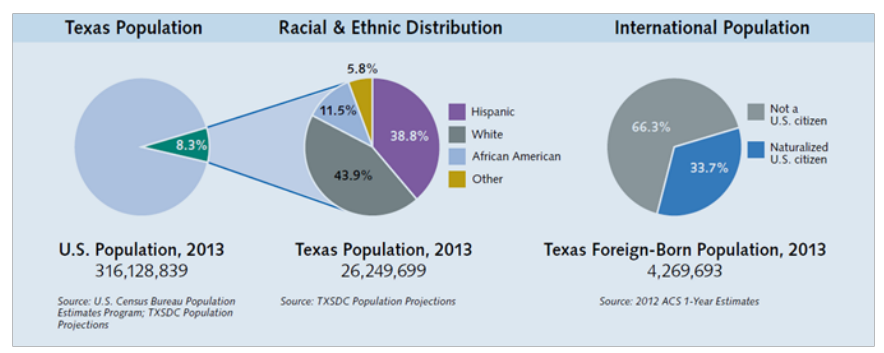

Fig. 13. Demografía de Texas. 
Respecto a las lenguas, en el estado de Texas, el 35,2\% de los hogares utiliza una lengua que no es el inglés, siendo la lengua española la predominante (www.thecb.state.tx.us). Incluso, en las poblaciones de la frontera con México, el inglés no es indispensable para la comunicación, ya que el uso del español está extendido en todos los ámbitos. Por ejemplo, el alcalde de El Cenizo, ciudad situada en la frontera, ha establecido como la lengua oficial el español, debido al gran porcentaje de hispanos en la ciudad, hecho que suscitó muchas polémicas en el país anglosajón. No obstante, por lo general, el uso del español depende mucho de quiénes sean los usuarios: recién llegados o hispanos nacidos en el país. La gran diferencia reside en que, en la mayoría de los casos -a pesar de un gran número de inmigrantes- se sigue el patrón generacional, como consecuencia del sistema educativo, ya que las escuelas de los diferentes distritos están sometidas a la Ley de Educación NCLB.

\subsection{Educación en Texas}

La educación bilingüe en Texas fue establecida en 1973, año en el que se firmó la ley Bilingual Education. Esta ley supuso un punto de inflexión histórico en la educación de los estudiantes de origen hispano. La clave de este programa fue el hecho de establecer que todas las escuelas primarias públicas de Texas en las que se matricularan 20 o más niños con limitado nivel de inglés debían adoptar la instrucción bilingüe. Esta cláusula sigue vigente hoy en día y presente en la Constitución del Estado, y, por consiguiente, el código de educación de Texas es un ejemplo para entender la forma y el objetivo del sistema educativo en EE.UU.

En primer lugar, en el título 2, subtítulo F, capítulo 29, subcapítulo B, Sec. 29.051 de la Constitución de Texas encontramos la política de estado respecto al programa educacional:

El inglés es el idioma básico de este estado. Las escuelas públicas son responsables de proporcionar una oportunidad plena para todos los estudiantes que sean competentes para hablar, leer, escribir y comprender el idioma inglés. [...] Los programas de educación y de lenguaje especial bilingües pueden satisfacer las necesidades de los estudiantes y facilitar su integración en el plan de estudios regular de la escuela.

En esta sección se puede observar el objetivo del sistema educativo bilingüe en Texas: proporcionar a los estudiantes con limitado dominio de inglés 
un nivel suficiente en esta lengua en los cuatro ámbitos que comprende el dominio lingüístico, ya que esta es la única manera de que los niños de familias inmigrantes tengan las mismas oportunidades que los nativos anglosajones, y puedan acceder a la educación superior.

Respecto a la educación bilingüe, las autoridades establecen que (Sec. 29.053):

(c) Cada distrito con una matrícula de 20 o más estudiantes de habilidad limitada del inglés en cualquier clasificación de las lenguas en el mismo grado escolar deberá ofrecer una educación bilingüe o programa de lenguaje especial.

(d) Cada distrito que se requiere para ofrecer una educación bilingüe y programas especiales de idiomas bajo esta sección se ofrece la siguiente información para los estudiantes de habilidad limitada del inglés:

1. la educación bilingüe en el kindergarten hasta los grados de primaria;

2. la educación bilingüe, la enseñanza de inglés como segunda lengua, o cualquier otra instrucción de lenguaje de transición aprobado por el organismo en los grados post- primaria hasta el grado 8 ; y

3. enseñanza de inglés como segundo idioma en los grados 9 al 12 .

Este apartado permite entender que la educación bilingüe comprende diferentes grados, dependiendo de cómo el alumno va asimilando el idioma, desde la preparatoria para la primaria ( 5 años) hasta finalizar la educación secundaria (14 años). La asimilación lingüística al idioma dominante es importante, ya que los exámenes exigidos por el organismo central - matemáticas, ciencias y estudios sociales, que comprenden la historia de Texas y de EE. UU., historia en general, etc.- se realizan en lengua inglesa. Los alumnos han de asistir a alguna asignatura de enriquecimiento, entre ellas el estudio de una lengua extranjera que suele comprender lengua castellana. Para obtener la graduación en la high school, el aprendizaje de una lengua extranjera también entra entre las asignaturas de libre elección (Title 19, Part 2, Chapter 74, Subchapter G, Rule 74.71).

Los programas bilingües más comunes y asequibles económicamente en Texas -según la Texas Education Agency (TEA) y destacados por Faltis (2011)- son los siguientes: 
1. Two-way. Los más frecuentes son 50:50 y 90:10; es decir, la instrucción se realiza tanto en la lengua materna de los alumnos como en inglés y la clase está compuesta por nativos anglosajones y nativos hispanohablantes. Estos programas son efectivos, ya que garantizan al alumno el conocimiento de su L1 y de la L2. El problema reside en que la lengua materna solo es una ayuda para que el alumno entre en el contacto con el inglés.

2. One-way. Comprende el mismo sistema de instrucción que el anterior, pero en una clase formada solo por hispanohablantes. El objetivo real de este programa es conseguir que el alumno adquiera un dominio del inglés suficiente para poder cursar los estudios posteriores impartidos solo en inglés.

3. Transitional bilingual late-exit y early-exit en los que la lengua de instrucción es el inglés y cuyo objetivo está claramente expresado en el informe de TEA:

Student proficiency in English and rapid mainstreaming into grade-level classes are the goals of transitional programs; therefore, these programs may be viewed, as "remediation" models where students are perceived as lacking in English skills and therefore in need of quick English remediation (TEA 2006).

4. ESL/content-based y ESL/pull-out. En este caso, la instrucción se realiza solo en inglés. La diferencia consiste en que, en el primer programa, la instrucción la realiza un profesor de inglés como segunda lengua, es decir, con ciertas nociones de español, mientras que en ESL pull-out la mayoría de las asignaturas son impartidas por profesores que solo dominan el inglés.

En pocas palabras, estamos ante los programas que más polémica han creado en el ámbito de la investigación de la educación bilingüe, ya que, en la mayoría de los casos, el alumno asimila la lengua dominante a costa de su lengua materna. Está demostrado que estos programas perjudican a los alumnos y que los programas bilingües que sirven de apoyo a la lengua materna son los más eficaces. El problema es que los programas bilingües son los que más coste generan a las arcas del Estado. Los programas transicionales son más económicos y, aunque

Effectiveness is a decided goal, but may not be the main political driver. Cost was a significant reason for California, Arizona, and Massachusetts' voters approval of English immersion programs. Most voters will vote in favor of cost-reducing measures (Faltis 2011: 92). 
Evidentemente, este sistema educativo puede dejar secuelas en los hispanohablantes, que, en la mayoría de los casos, experimentan la sustitución lingüística. Por consiguiente, muchos individuos de origen latino no poseen un buen dominio del español. Aunque en algunos casos hay intentos de recuperación del idioma -generalmente en las universidades que ofrecen asignaturas de español como lengua hereditaria o como lengua adicional-, el ambiente anglosajón y la presión social suelen determinar la elección de la lengua.

\section{2 "Spanish in Texas"}

El Spanish in Texas es parte del programa 2010-2014 del Center for Open Educational Resources and Language Learning (COERLL), un National Foreign Language Resource Center en la Universidad de Texas en Austin. El objetivo de este programa es analizar la variación lingüística del español en Texas, como consecuencia del constante contacto entre el español y el inglés. En su corpus ofrecen vídeos de hispanohablantes bilingües con sus correspondientes transcripciones, con el objetivo de animar a los demás a conocer la lengua y la cultura. A partir de los vídeos disponibles en su corpus podemos acercarnos a la situación del español en Texas e intentar determinar de qué situación se trata.

En total, hemos analizado 212 vídeos en los que participan 43 individuos. Los vídeos analizados tratan el tema del idioma y de la identidad. Los entrevistados están clasificados según el lugar de nacimiento (nacidos en el extranjero o foreign born versus nacidos en EE.UU. o US born) y la edad, que comprende tres grupos: 18-24, 25-44, 45-64. En concreto, los nacidos en el extranjero constituyen un grupo de 15 individuos y los nacidos en Estados Unidos un bloque de 28 personas. Las preguntas respondidas por la mayoría los participantes son las siguientes:

- ¿Qué lenguas utilizas con tus familiares?

- ¿Dónde sueles hablar en español?

- ¿Utilizas spanglish?

- ¿En qué lengua te diriges a un hispano por primera vez?

- ¿Qué importancia tiene para ti el bilingüismo?

Los resultados están agrupados de la siguiente forma:

1. En primer lugar, intentamos observar si hay diferencia entre las respuestas proporcionadas por los individuos dependiendo de su lugar de nacimiento. 
2. En segundo lugar, nos interesa analizar las respuestas ofrecidas por el grupo de individuos de edades comprendidas entre 45-64 años.

3. En tercer lugar, realizamos un análisis de conjunto para intentar determinar la situación del español a partir de las respuestas proporcionadas por todos participantes del estudio.

\section{Diferencias según el Lugar de Nacimiento}

\section{Foreign Born}

Respecto al primer análisis, hemos podido observar que la gran mayoría de los 15 individuos nacidos en el extranjero (Foreign born) utiliza en la comunicación con los familiares el español (7), 6 de ellos el inglés y 2 se sirven tanto del español como del inglés.

Hay que destacar que, un número importante (10) utiliza el español en el ámbito familiar y el resto (5) en sus puestos de trabajo o en el ámbito de la educación.

Por otra parte, el uso de spanglish es muy común, ya que solo 3 individuos de los 15 entrevistados han reconocido no utilizar esa lengua criolla.

Respecto a la elección de la lengua cuando conocen a un hispano por primera vez, 4 de los 15 suelen iniciar la comunicación en inglés y el resto reconoce que la elección de la lengua depende de los factores contextuales.

En lo referente a la importancia del bilingüismo, prevalece la opinión de que ser bilingüe ofrece nuevas oportunidades en el mundo laboral, aunque 6 de las 15 personas entrevistadas han reconocido que la importancia del bilingüismo consiste en la mejora de la comunicación entre los diferentes grupos lingüísticos.

Estos resultados están representados en la Figura 14.

\section{US Born}

Respecto la primera pregunta, los nacidos en EE.UU. reconocen que en la comunicación con sus familiares utilizan el inglés (13), algunos el inglés y el español (10) y tan solo 5 de los 28 entrevistados afirman que con sus familiares hablan en español.

La gran mayoría utiliza el español en el ámbito familiar (18), 6 de los 28 en su puesto de trabajo o en la escuela, 3 tanto en el ámbito familiar como laboral y 1 persona no habla español a diario, solo ocasionalmente. 


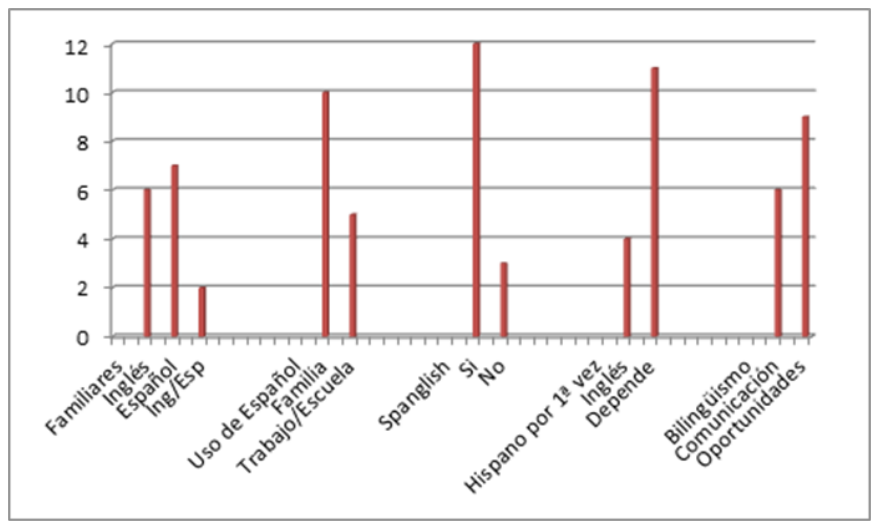

Fig. 14. Uso de español entre los hispanos nacidos fuera de EE.UU.

En lo referente al spanglish, 23 de los 28 participantes reconoce que lo utiliza muy a menudo, en contraste con los 5 individuos que ni lo usan ni muestran una actitud positiva hacia la mezcla de los dos idiomas.

13 de los 28 individuos de este bloque reconocen que, al conocer a un hispano por primera vez, se dirigen a él en inglés. 15 hispanos afirman que la elección de la lengua depende de la ocasión y el lugar en el cual conocen al desconocido de origen latino.

Por último, para la mayoría el bilingüismo abre las puertas al mundo laboral, aunque 12 personas consideran que también es importante para la mejor comunicación.

\section{Grupo de Edad Comprendido entre los 45-64 Años}

Analizamos ahora el grupo de individuos nacidos en Estados Unidos con edades comprendidas entre 45 y 64 años. A pesar de que este grupo está integrado por solo cinco personas, lo hemos escogido con la intención de ilustrar la transmisión intergeneracional de la lengua española.

Respecto a la primera pregunta - que trata el tema de la comunicación con familiares-, en este caso se ha preguntado por la lengua que estos individuos utilizan en la comunicación con sus hijos desde la infancia hasta la actualidad. Lo más sorprendente, como puede observarse en la Figura 17, es que 4 de las 5 personas reconocen que con sus hijos hablaban y hablan solo el inglés. Aunque 


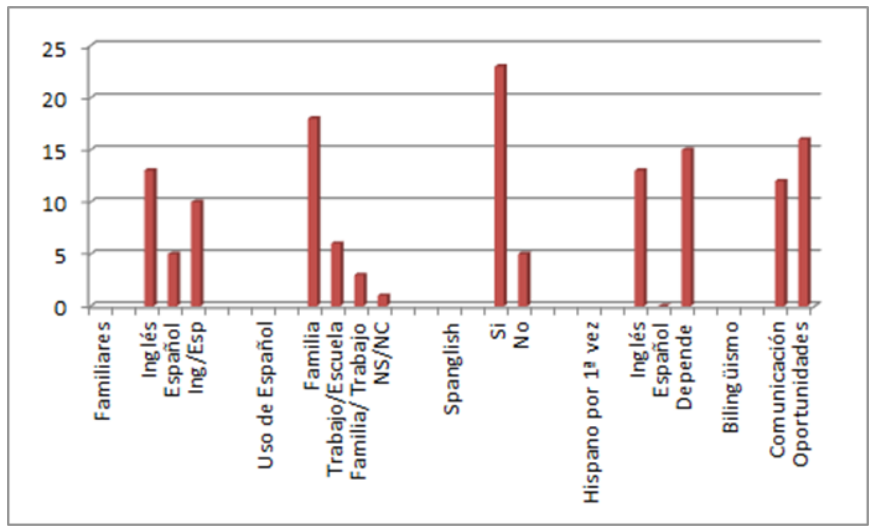

Fig. 15. Uso de español entre los hispanos nacidos en EE.UU.

se trata solo de 5 personas, es evidente que la transmisión del español, en estos casos, es nula. Por tanto, estas personas confirman el patrón generacional de la población hispana de EE.UU. (Figura 16).

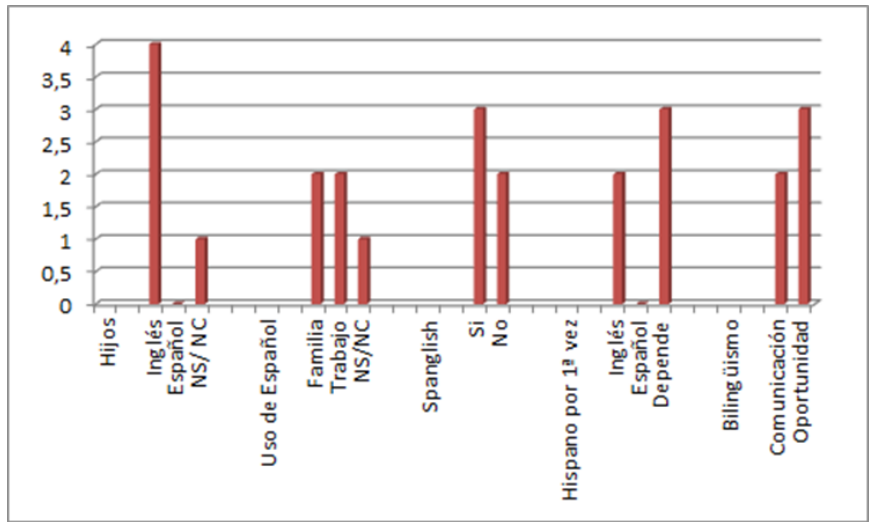

Fig. 16. Transmisión intergeneracional entre hispanos nacidos en EE.UU. 


\section{Análisis de Conjunto}

Respecto al uso de la lengua española entre los hispanos entrevistados en su conjunto, los resultados muestran (Figura 17) que la gran mayoría de los entrevistados:

- Usan el inglés como lengua de comunicación con sus familiares.

- Restringen el uso de español al ámbito familiar.

- Utilizan el spanglish.

- Al dirigirse a una persona de origen hispano eligen la lengua según el contexto, ya que muchos latinos no hablan español.

- Consideran que el bilingüismo ofrece nuevas oportunidades en el ámbito laboral.

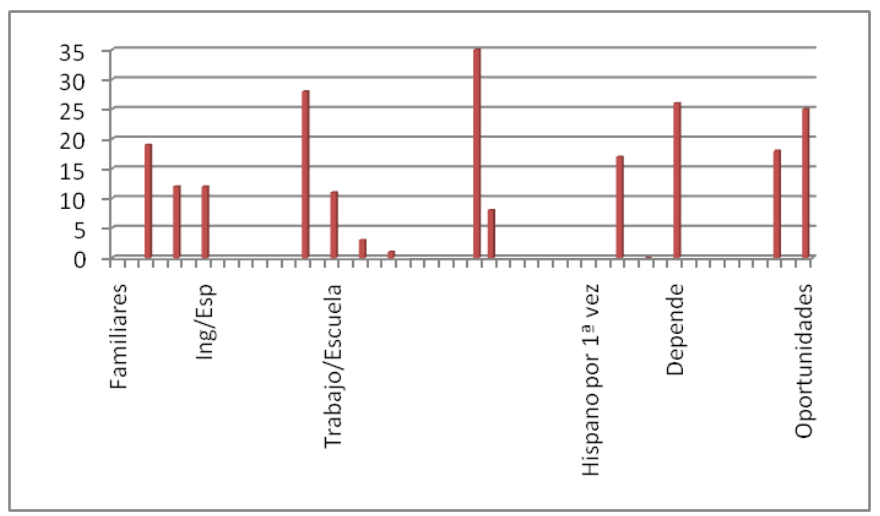

Fig. 17. Uso del español entre hispanos en EE.UU.

\subsection{Actitud de los Tejanos}

Para poder determinar tanto la situación actual como el posible futuro de la lengua española en Texas, hay que tener en cuenta la opinión de los norteamericanos, no solo la actitud de los órganos políticos. En concreto, hay que prestar atención a la actitud de los estadounidenses respecto a la lengua española. Con el objetivo de recoger las opiniones de los ciudadanos de los 
EE.UU., hemos elaborado y realizado una mini-encuesta formada por solo dos preguntas:

1. ¿Está usted a favor de la educación bilingüe?

2. Con la creciente presencia del español en Texas ¿estaría usted a favor de que el español fuera lengua cooficial en Estados Unidos?

La encuesta ha sido creada a través de la página Survey Monkey. Los encuestados, para responder a las preguntas, solo tenían que seguir el enlace https : //es.surveymonkey.com/s/GMW536P. La encuesta se ha difundido a través de la red social www.meetme.com, que ofrece la opción de encontrar usuarios según el país. En este caso, nos ha permitido seleccionar personas residentes en el estado de Texas. Hemos enviado un total de 200 mensajes, y obtenido tan solo 20 respuestas Aunque la representatividad de la muestra no es alta, las respuestas obtenidas y los comentarios que han hecho algunos de los encuestados, nos ha permitido reflexionar sobre la actitud de los norteamericanos hacia la lengua española.

Respecto a la primera pregunta, el $55 \%$ de los encuestados está a favor de la educación bilingüe, en contraste con el $45 \%$ que no apoya este tipo de educación (Figura 18).

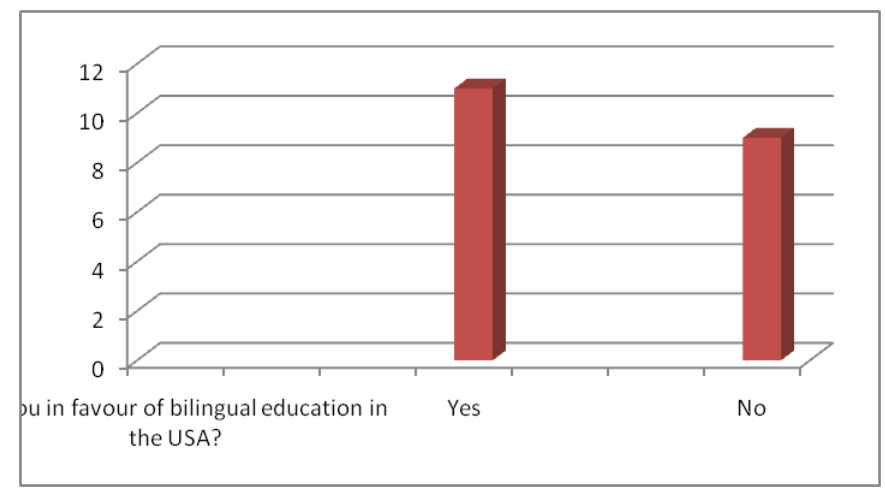

Fig. 18. Resultados de la opinión anglosajona respecto a la educación bilingüe.

Las respuestas a la segunda pregunta ofrecen la siguiente perspectiva de la actitud de los norteamericanos (Figura 19). 


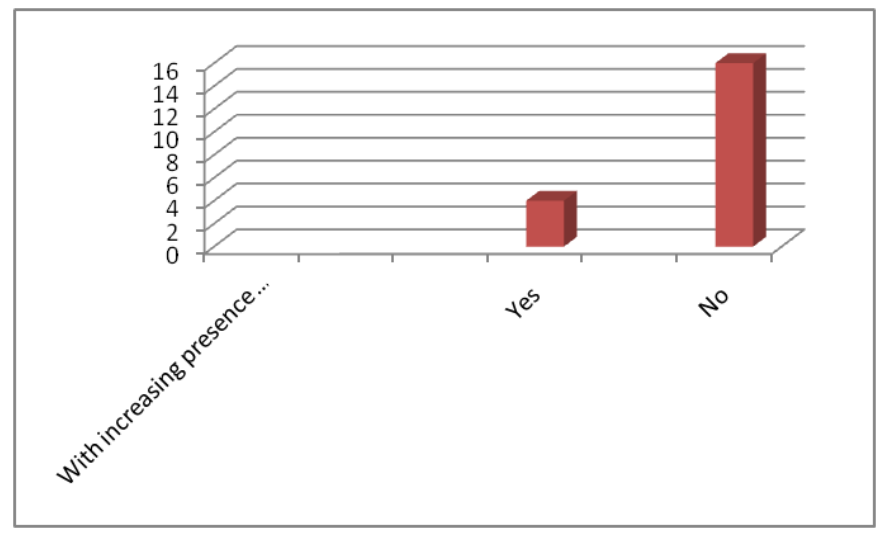

Fig. 19. Resultados de la encuesta sobre la actitud norteamericana sobre español como lengua cooficial.

La actitud de los norteamericanos de Texas al parecer no es muy positiva hacia el español, ya que, aunque el $55 \%$ de los encuestados están a favor de la educación bilingüe, la gran mayoría rechaza la idea de que el español sea la lengua cooficial de EE.UU.

Por tanto, según los resultados obtenidos, puede afirmarse que el español en Texas pasa por una situación más bien de carácter diglósico que bilingüe, ya que el español no está presente en los mismos ámbitos de uso que la lengua dominante.

El español es la lengua para los asuntos privados, aunque cada vez más se está convirtiendo también en la lengua del ámbito laboral, ya que son muchas las empresas de propiedad española o latinoamericana que apuestan por el mercado estadounidense. No es de sorprender que, según el Rice University Kinder Institute for Urban Reseach, las entrevistas de trabajo en español hayan aumentado de un 10,5\% a un 22,1\% desde 2007 a 2014. Eso quiere decir que cada vez más empresas están interesadas en la contratación de bilingües, debido a las exigencias del mercado. Por tanto, la lengua española se está convirtiendo en un idioma de negocios y, si esta tendencia sigue el mismo ritmo, en el futuro podríamos hablar de una situación de bilingüismo en la comunidad de habla, según Andrew Lynch (2013), relacionada con el ámbito de negocios y laboral. 


\section{Conclusiones}

Lo lógico sería esperar que en una zona con alta concertación de hispanos, estuviéramos ante una situación de bilingüismo, pero la situación del español en EE.UU., según los datos presentados, muestra que estamos ante las características típicas de una situación de diglosia y no de una situación de bilingüismo, a pesar de la gran presencia hispana en territorio estadounidense.

Es cierto que el español está cada vez más presente en los ámbitos públicos, no obstante, creemos que, la realidad lingüística de los individuos hispanos en la Unión no puede basarse únicamente en una serie de buenas intenciones por parte de las autoridades que se reducen a ofrecer información sobre los principales servicios públicos en español. La elección lingüística y el consiguiente uso de una lengua determinada (español o inglés) por parte de los hispanos están condicionados por la actitud tanto de los norteamericanos como de los órganos políticos que los representan.

La población anglosajona muestra una actitud claramente negativa hacia la educación bilingüe en español. Esta actitud podría estar causada por cierto temor a que la lengua española - debido al gran número de población hispanapueda ganar terreno al inglés, causando una hipotética sustitución lingüística.

La actitud negativa de la población anglosajona se refleja en las políticas lingüísticas adoptadas por el gobierno central, en concreto, la sustitución de la ley que garantizaba la educación bilingüe a los inmigrantes, por la ley aprobada en 2001, No Child Left Behind, por el gobierno del partido republicano. Esta ley, como se ha mostrado, apoya el monolingüismo y es de tipo asimilacionista.

La principal consecuencia que se deriva del sistema estadounidense es la débil transmisión intergeneracional, que puede observarse a partir de las segundas generaciones de hispanos, ya nacidas en EE.UU. Este hecho refleja y potencia el patrón generacional que consiste en el desplazamiento lingüístico del español por la lengua dominante. A esto hay que añadir la inferioridad lingüística de la gran mayoría de la población de origen mexicano, ya que, en muchos casos, los recién llegados no pueden obtener el acceso a la educación formal por las condiciones sociales en su país de origen.

Por tanto, teniendo en cuenta las políticas lingüísticas, la actitud norteamericana, el sentimiento de inferioridad lingüística por parte de los muchos latinos y la poco efectiva transmisión intergeneracional, el español en los Estados Unidos, creemos, presenta una situación diglósica. 
Desde el punto de vista de la definición de Ferguson (1959), estamos ante diglosia ya que, como se ha mostrado, en la mayoría de los casos, el español tiene una función determinada, principalmente en el ámbito familiar.

Desde el punto de vista de la concepción de diglosia de Fishman (1979), estamos ante el bilingüismo sin diglosia, ya que la lengua dominante acaba imponiéndose y acaba sustituyendo a la lengua materna, es decir, el patrón generacional.

Muchos estudiosos, entre ellos April Linton (2004), consideran que el bilingüismo se da y se mantendrá en el ámbito económico; pero, solo en el caso que dominar otro idioma resulte una ventaja en el mercado. Por consiguiente, mantener el español será viable en áreas donde los incentivos para el bilingüismo sean superiores a los incentivos para el monolingüismo. Es decir, estamos ante un modelo de bilingüismo cuya base es coste/beneficio: un menor coste para la elección del idioma lleva a mayor beneficio en incentivos (Linton 2004). Este podría ser un ejemplo de posible motivación para mantener y transmitir el español entre los hispanos en suelo estadounidense. Es decir, esta sería una vía para llegar a una situación de bilingüismo en EE.UU., aunque solo a nivel económico y laboral. Tal vez, esto reforzaría la posición social de la gran mayoría de hispanos, ya que, como se demuestra en actualidad, el bilingüismo se mantiene solo en los grupos de alto estatus, por ejemplo, los cubanos en Florida (Linton 2004: 296).

Aclaradas las circunstancias por las que pasa la lengua española en EE.UU., es difícil llegar a unas conclusiones positivas respecto a las expectativas defendidas actualmente por muchos especialistas que opinan que Estados Unidos será el primer país hispanohablante en 2050. A partir de los resultados obtenidos en este trabajo, defendemos lo siguiente:

1. No hay que confundir la lengua con el origen de un individuo o su raza. Es decir, a pesar de que las estadísticas y las previsiones aseguran un crecimiento de la población hispana en los próximos años, no hay que olvidar que la vitalidad del español en la Unión se debe en gran parte a la inmigración que, a su vez, depende de las decisiones respecto a las políticas migratorias que adopta el gobierno central.

2. Ser hispano no conlleva el supuesto de dominar y usar el español. Los censos no aportan la información respecto al dominio del español. Y como el español depende de la transmisión intergeneracional, es casi imposible determinar qué nivel de español tienen los hispanos en EE.UU., mucho 
más si tenemos en cuenta la tendencia que sigue la transmisión de la lengua de generación en generación.

3. La elección de la lengua no depende solamente del país de origen de un individuo. La elección suele realizarse a partir de las condiciones extralingüísticas que acompañan a las personas en sus vidas cotidianas. Es decir, la presión social y los prejuicios de los miembros tanto del mismo grupo lingüístico como de otros distintos. Teniendo en cuenta el contexto estadounidense, los problemas de la educación bilingüe y la actitud del pueblo norteamericano hacia el español, es difícil pensar que los hispanos no sean asimilados a la lengua dominante abandonando la propia.

4. Las políticas lingüisticas son el factor determinante. Las decisiones de los órganos políticos responsables del ámbito lingüístico determinan, mediante las leyes, qué lengua es la dominante, primordialmente reflejada en el ámbito de la educación. EE.UU. muestra una clara preferencia por el monolingüismo.

5. Los ámbitos político y económico son los que determinan la elección de la lengua por la gran mayoría de los hablantes en la era de la globalización y, en casos como el español en EE.UU., en qué lugar se ha de emplear dicha lengua. En el caso del español en EE.UU., como se ha mostrado, el mantenimiento del español y, por consiguiente, el bilingüismo resulta ser beneficioso en el ámbito laboral.

Por tanto, el futuro de la lengua española en EE.UU. en 2050 es difícil de prever, sin embargo en la era global y con la importancia del mercado de los países de habla hispana, el español podría convertirse en otra lingua franca del mismo nivel y la misma importancia que el inglés, pero en la comunidad de habla que comprende el ámbito de los negocios, tanto entre los hispanohablantes nativos como los no nativos. Esta perspectiva podría potenciar la transmisión intergeneracional entre los latinos en EE.UU. y, tal vez, este podría ser el punto de partida para la expansión del español en EE.UU., convirtiéndolo en el mayor país hispanohablante.

Para finalizar, hay que destacar que el futuro inmediato del español en EE.UU. depende principalmente de las políticas lingüísticas que adopte el gobierno estadounidense, ya que hasta que no se abandone esa actitud de supremacía lingüística del inglés, no se deje de menospreciar el bilingüismo y no se acepte que la presencia de otras lenguas en territorio estadounidense puede beneficiar no solo a los bilingües sino también a los monolingües an- 
glosajones, la lengua española y todos los hispanohablantes no podrán compartir el sueño americano, o en palabras de Samuel P. Huntington:

"American dream" often tends to be one that is created by an Anglo-Protestant society, and linguistic minorities "will share in that dream and in that society only if they dream in English" (citado por Harper 2011: 528).

\section{Bibliografía}

1. Abelló Contesse, Ch. \& Ehlers, Ch. (2010). Escenarios bilingües: una visión global. In Abelló Contesse, Ch., Ehlers, Ch. \& Quintana Hernández, L. (eds), Escenarios bilingües. El contacto de lenguas en el individuo y la sociedad (pp. 7-42). Bern: Peter Lang.

2. Alvar, M. (1990). La lengua, los dialectos y la cuestión del prestigio. In Moreno Fernández, F. (coord.), Estudios sobre variación lingüistica (pp. 13-25). Alcalá de Henares: Universidad de Alcalá de Henares.

3. Appel, R. \& Muysken, P. (1996). Bilingüismo y contacto de lenguas. Barcelona: Ariel.

4. Baker, C. (1992). Attitudes and language. Clevedon: Multilingual Matters LTD.

5. Baker, C. (2006). Foundations of bilingual education and bilingualism. Clevendon: Multilingual Matters LTD.

6. Bhatia. T.K. \& Ritchie W.C. (2012). The handbook of bilingualism and multilingualism. Oxford: Wiley-Blackwell.

7. Bloomfield, L. (1933). Language. Nueva York: H. Holt \& Co.. Traducción al español: Lenguaje. Lima: Universidad Mayor de San Marcos, 1964.

8. Bullock, B.E. \& Toribio, A.J. (2013). The Spanish in Texas Corpus Project. COERLL. Austin: The University of Texas at Austin.

9. Bustamante-López, I. (2008). Constructing linguistic identity in Southern California. In Niño-Murcia, M. \& Rothman, J. (eds.), Bilingualism and Identity: Spanish at the crossroads with other languages (pp. 279-300). Amsterdam: John Benjamins.

10. Centro Virtual Cervantes (2008). Enciclopedia del español en los Estados Unidos. Anuario del Instituto Cervantes.

11. Centro Virtual Cervantes (2012). El español en el mundo. Anuario del Instituto Cervantes.

12. Díaz Campos, M. (2014). Introducción a la sociolingüística hispánica. Oxford: Wiley-Blackwell.

13. Dimitrescu, D. (2013). El español en Estados Unidos a la luz del censo de 2010: los retos de las próximas décadas. Hispania, 96(3): 525-541. 
14. Eckert, P. (2009). Linguistic variation as social practice. Oxford: Blackwell.

15. Faltis, K. (2011). Bilingual, ESL, and English Immersion: Educational Models for Limited English Proficient Students in Texas. Pepperdine Policy Review.

16. Farr, M. \& Domínguez-Barajas, E. (2005a). Introduction: Latinos, Language and Identity at Home, School, Church, and Work. In Farr, M. (ed.), Latino Language and Literacy in Ethnolinguistic Chicago (pp. 3-32). Mahwah: Lawrence Erlbaum Associates.

17. Farr, M. \& Domínguez-Barajas, E. (2005b). Sociocognitive aspects of proverb use in a Mexican transnational social network. In Farr, M. (ed.), Latino Language and Literacy in Ethnolinguistic Chicago (pp. 67-95). Mahwah: Lawrence Erlbaum Associates.

18. Fasold, R. (1996). La sociolingüistica de la sociedad. Introducción a la sociolingüistica. Madrid: Visor Libros.

19. Ferguson, Ch. (1959). Diglossia. Word, 15: 325-340.

20. Fishman, J. (1972). Sociología del lenguaje. Madrid: Cátedra.

21. Fishman, J.A. (1989). Language and ethnicity in minority sociolinguistic perspective. Clevedon: Multilingual Matters LTD.

22. Fishman, J.A. (1991). Reversing language shift. Theorical and empirical foundations of assitance to threatened languages. Clevendon: Multilingual Matters LTD.

23. Gal, S. (1979). Language shift: social determinants of linguistic change in bilingual Austria. New York: Academic Press.

24. García, C. (2013). El mito del español en Estados Unidos. The Huffington Post.

25. Hall, Ch. J. (2005). An introduction to language and linguistics. Breaking the language spell. London: Continuum.

26. Harper, S.M. (2011). Counting the costs of a global anglophonic hegemony: Examining the impact of U.S. language education policy on linguistic minorities worldwide. Indiana Journal of Global Legal Studies, 18(1): 515-538.

27. Hugo López, M. \& Gonzales-Barrera, A. (2013). What is the future of Spanish in the United States? PewResearch Center.

28. Linton, A. (2004). A Critical Mass Model of Bilingualism among U.S.-Born Hispanics. Social Forces, 83(1): 279-314.

29. López Morales, H. (1990). La sociolingüística actual. In Moreno Fernández, F. (coord.), Estudios sobre variación lingǘstica (pp. 79-88). Alcalá de Henares: Universidad de Alcalá de Henares.

30. López Morales, H. (2008). Hoy... ¿y mañana? Enciclopedia del español en Estados Unidos. Anuario del Instituto Cervantes.

31. Lynch, A. (2008). Monolingüismo. Latinos e hispanohablantes: grados de dominio del español. Mexicanos. Enciclopedia del español en Estados Unidos. Anuario del Instituto Cervantes.

32. Lynch, A. (2013). Observaciones sobre comunidad y (dis)continuidad en el estudio sociolingüístico del español en Estados Unidos. In Dumitrescu, D. \& Piña- 
Rosales, G. (eds.), El español en los Estados Unidos: E pluribusunum? Enfoques multidisciplinarios (pp. 67-83). New York: Academia Norteamericana de la Lengua Española.

33. Lynch, A. \& Klee, C.A. (2005). Estudio comparativo de actitudes hacia el español en los Estados Unidos: educación, política y entorno social. Lingüistica Española Actual, 27: 273-300.

34. Lynch, A. \& Potowski, K. (2014). La valorización del habla bilingüe en los Estados Unidos: fundamentos sociolingüísticos y pedagógicos en Hablando bien se entiende la gente. Hispania, 97(1): 32-46.

35. Mackey, W.F. (2012). Bilingualism and multilingualism in North America. In Bhatia. T.K. \& Ritchie W.C. (eds.), The handbook of bilingualism and multilingualism (pp. 707-718). Oxford: Wiley-Blackwell.

36. Macnamara, J. (1969). How can one measure the extent of a person's bilingual proficiency? In Kelly, L. G. (ed.), Description and Measurement of Bilingualism: An International Seminar. Toronto: University of Toronto Press.

37. Mar-Molinero, C. (2009). Forces of globalization in the Spanish-speaking world: linguistic imperialism or grassroots adaptation. In Mar-Molinero, C. \& Stewart, M. (eds.), Forces of globalization in the Spanish-speaking world. Macro and micro perspective (pp. 8-26). Palgrave: MacMillan.

38. Ministerio de Educación (2012-2013). Guía para profesores visitantes en el estado de Nuevo México. Consejería de Educación, Embajada de Estados Unidos.

39. Ministerio de Educación (2014-2015). Guía para profesores visitantes en el estado de Nuevo México. Consejería de Educación, Embajada de Estados Unidos.

40. Montrul, S. (2013). El bilingüismo en el mundo hispanohablante. Oxford: WileyBlackwell.

41. Moreno Fernández, F. (1990). Las reglas del método sociolingüístico. In Moreno Fernández, F. (coord.), Estudios sobre variación lingüistica (pp. 105-113). Alcalá de Henares: Universidad de Alcalá de Henares.

42. Moreno Fernández, F. (2004). El fututo de la lengua española en los EEUU. Real Instituto Elcano, 10: 4-8.

43. Moreno Fernández, F. (2009). Principios de sociolingüistica y sociología del lenguaje. Barcelona: Ariel.

44. Moreno Fernández, F. (2013a). El factor hispano: cantidades, cualidades y debate. Tribuna Norteamericana, 12.

45. Moreno Fernández, F. (2013b). Panorama interdisciplinario del español en los Estados Unidos. Tribuna Norteamericana, 3.

46. Myers-Scotton, C. (2006). Multiple voices: An introduction to bilingualism. Malden: Blackwell.

47. Ninyoles, R. Ll. (1972). Idioma y poder social. Madrid: Tecnos.

48. Patten, E. \& Brown A. (2014). Statistical Portrait of Hispanics in the United States, 2012. PewResearch Hispanic Project.

49. PewResearch Center (2009). Between Two Worlds. How Young Latinos Come of Age in America. 
50. Pomerantz, A. \& Huguet, Á. (2007). La enseñanza del español en las escuelas públicas de los Estados Unidos de América: ¿bilingüismo para quién? Infancia y aprendizaje, 36(4): 517-536.

51. Prados, E. \& Delgado, M. (2007). Televisión hispana en Estados Unidos. Tensiones económicas y cambios generacionales. Telos, 70: 74-84.

52. Rhodes, N. \& Pufahl, I. (2014). Panorama de la enseñanza de español en las escuelas de los Estados Unidos. Resultados de la encuesta nacional. Observatorio de la lengua española y las culturas hispánicas en los Estados Unidos.

53. Riley, P. (2007). Language, culture and identity: an ethnolinguistic perspective. London: Continuum.

54. Rolle, R. A. \& Jiménez-Castellanos, O. (2014). An Efficacy of the Texas School Funding Formula with particular attention to English Language Learners. Journal of Education Finance, 39(3): 203-221.

55. Romaine, S. (1982). Sociolinguistis variation in speech communities. London: Edwart Arnold.

56. Salzmann, Z. (1998). Language, culture and society. An introduction to linguistic anthropology. Boulder: West view Press.

57. Saussure, F. (1916). Curso de lingüisica general. Buenos Aires: Losada, 1945.

58. Schecter, S. \& Bayley, R. (2002). Language as cultural practice. Mexicanos en el norte. Mahwah: Lawrence Erlbaum Associates.

59. Siguán, M. (2001). Bilingüismo y lenguas en contacto. Barcelona: Alianza Editorial.

60. Siguán, M. \& Mackey, W.F. (1989). Educación y bilingüismo. Madrid: Santillana.

61. Silverstein, M. (2003). The whens and wheres -as well as hows- of ethnolinguistic recognition. Public Culture, 15(3): 531-557.

62. Skutnabb-Kangas, T. (1981). Bilingualism or not: the education of minorities. Clevendon: Multilinguals Matters.

63. Stewner-Manzanares, G. (1988). The Bilingual Education Act: Twenty Years Later. New Focus, 6: 1-10.

64. Suárez-Orozco, C. \& Suárez-Orozco, M. (2001). Children of immigration. Cambridge: Harvard University Press.

65. Titone, R. (1976). Bilingüismo y educación. Barcelona: Fontanella.

66. Trudgill, P. \& Hernández Campoy, J. M. (2007). Diccionario de sociolingüistica. Madrid: Gredos.

67. Weinreich, U. (1953). Languages in contact: Findings and problems. Traducción española: Lenguas en contacto. Descubrimientos y problemas. Caracas: Universidad Central de Venezuela, Ediciones de la Biblioteca, 1974.

68. Wright, W. E. (2012). Bilingual education. In Bhatia, T. \& Ritchie, W. C. (eds), The handbook of bilingualism and multilingualism (pp. 598-623). Oxford: Wiley-Blackwell.

\section{Sitios Web}


69. ABC, www.abc.es [Consulta: Abril 2014]

70. American Fact Finder, https : //factfinder.census.gov/ [Consulta: Mayo 2014]

71. Casa Blanca, www.whitehouse.gov/ [Consulta: Abril 2014]

72. Centro de Estadísticas Nielsen, www.nielsen.com [Consulta: Junio 2014]

73. Centro Virtual Cervantes, cvc.cervantes.es/ [Consulta: Abril 2014]

74. Constitución de Texas, http : //www.statutes.legis.state.tx.us/ [Consulta: Mayo 2014]

75. El Mundo, http : //www.elmundo.es/ [Consulta: Abril 2014]

76. El País, elpais.com [Consulta: Abril 2014]

77. Gobierno de Texas, www.texas.gov/ [Consulta: Mayo 2014]

78. Instituto Cervantes, www.cervantes.es [Consulta: Abril 2014]

79. Meetme, www.meetme.com [Consulta: Mayo 2014]

80. Modern Language Association, http : //www.mla.org/ [Consulta: Junio 2014]

81. National Center for Education Statistics, https : //nces.ed.gov/ [Consulta: Mayo 2014]

82. Observatorio de la lengua española y las culturas hispánicas en los Estados Unidos, http : //cervantesobservatorio.fas.harvard.edu/es [Consulta: Abril 2014]

83. Online Newspaper com, http://www.onlinenewspapers.com/usstate/spanishlanguage - newspapers - usa.htm [Consulta: Mayo 2014]

84. PewResearch Hispanic Trends Project, http : //www.pewhispanic.org/ [Consulta: Junio 2014]

85. Prensa Libre, http : //www.prensalibre.com/ [Consulta: Junio 2014]

86. Project Muse, http://muse.jhu.edu/ [Consulta: Junio 2014]

87. Real Academia Española, www.rae.es [Consulta: Mayo 2014]

88. Spanish in Texas, www.spanishintexas.org/ [Consulta: Abril 2014]

89. Survey Monkey, https : //es.surveymonkey.com/ [Consulta: Mayo 2014]

90. Texas Education Agency, www.tea.state.tx.us/ [Consulta: Abril 2014]

91. Texas Dual Language Program Cost Analysis, http : //www.lwvirving.org/files/dual_language_cost_analysis.pdf [Consulta: Mayo 2014]

92. Texas Higher Education Coordinating Board, http : //www.thecb.state.tx.us/ [Consulta: Abril 2014]

93. The Huufington Post's Latino Voices, http : //www.huffingtonpost.com/latino - voices / [Consulta: Junio 2014]

94. The State of the News Media 2011. Pew Research Center Project for Excellence in Journalism, http : //stateofthemedia.org/2011/hispanic-media-fairingbetter - than - the - mainstream - media/ [Consulta: Junio 2014]

95. United States Census Bureau, http ://www.census.gov/[Consulta: Mayo 2014]

96. United States Department of Labor, http : //www.bls.gov/ [Consulta: Mayo 2014]

97. Universidad de Harvard, www.harvard.edu/ [Consulta: Abril 2014] 
98. Universidad de Houston, www.uh.edu/ [Consulta: Abril 2014] 99. Universidad de Texas, www.utexas.edu/[Consulta: Abril 2014] 100. U.S Departament of Education, www.ed.gov/ [Consulta: Mayo 2014]

\section{Biodata}

Anna Orlovska es estudiante de la Universitat Rovira i Virgili desde el año 2010. Graduada en Lengua y Literatura Hispánicas (2010-2014), Máster en Enseñanza de español como lengua extranjera (2014-2015) y actualmente estudiante de doctorado. Ha impartido clases de español a alumnos chinos durante la realización del Máster de Enseñanza de Español como Lengua Extranjera y, como parte de la beca de la Generalitat de Catalunya, ha participado en un proyecto del Departamento del Filologies Romàniques de la URV, relacionado con el futuro cambio del plan de estudios del mismo. Su principal área de investigación es la complejidad lingüística desde la interdisciplinariedad, en concreto, la aplicación de técnicas computacionales al análisis de la complejidad lingüística, con especial interés en el aprendizaje de segundas lenguas. 